IZA DP No. 7914

How Urbanization Affects Employment and Social Interactions

Yasuhiro Sato

Yves Zenou

January 2014 


\title{
How Urbanization Affects Employment and Social Interactions
}

\author{
Yasuhiro Sato \\ Osaka University \\ Yves Zenou \\ Stockholm University, \\ IFN, CEPR and IZA
}

\section{Discussion Paper No. 7914 \\ January 2014}

IZA
P.O. Box 7240
53072 Bonn
Germany

Phone: +49-228-3894-0

Fax: +49-228-3894-180

E-mail: iza@iza.org

Any opinions expressed here are those of the author(s) and not those of IZA. Research published in this series may include views on policy, but the institute itself takes no institutional policy positions. The IZA research network is committed to the IZA Guiding Principles of Research Integrity.

The Institute for the Study of Labor (IZA) in Bonn is a local and virtual international research center and a place of communication between science, politics and business. IZA is an independent nonprofit organization supported by Deutsche Post Foundation. The center is associated with the University of Bonn and offers a stimulating research environment through its international network, workshops and conferences, data service, project support, research visits and doctoral program. IZA engages in (i) original and internationally competitive research in all fields of labor economics, (ii) development of policy concepts, and (iii) dissemination of research results and concepts to the interested public.

IZA Discussion Papers often represent preliminary work and are circulated to encourage discussion. Citation of such a paper should account for its provisional character. A revised version may be available directly from the author. 
IZA Discussion Paper No. 7914

January 2014

\section{ABSTRACT}

\section{How Urbanization Affects Employment and Social Interactions}

We develop a model where the unemployed workers in the city can find a job either directly or through weak or strong ties. We show that, in denser areas, individuals choose to interact with more people and meet more random encounters (weak ties) than in sparsely populated areas. We also demonstrate that, for a low urbanization level, there is a unique steady-state equilibrium where workers do not interact with weak ties, while, for a high level of urbanization, there is a unique steady-state equilibrium with full social interactions. We show that these equilibria are usually not socially efficient when the urban population has an intermediate size because there are too few social interactions compared to the social optimum. Finally, even when social interactions are optimal, we show that there is overurbanization in equilibrium.

JEL Classification: J61, R14, R23

Keywords: weak ties, strong ties, social interactions, urban economics, labor market

Corresponding author:

Yves Zenou

Stockholm University

Department of Economics

10691 Stockholm

Sweden

E-mail: yves.zenou@ne.su.se 


\section{Introduction}

It is well-established that in denser and more populated areas (such as big cities), individuals have more random contacts (weak ties) and thus are more likely to have bigger networks than in less dense areas. Sociologists argue that relationships in large cities are less personal. People in large cities, in comparison with people in small towns or rural areas, experience general deficits in the quality of interpersonal relations (strong ties). ${ }^{1}$ However, people in small towns or rural areas base their social networks on the limited number of people who live nearby whereas people in large cities have a great deal of choice in constructing their social networks and can seek out others with similar values, interests, and life-styles. ${ }^{2}$ As a result, urbanites are less likely than rural dwellers to base their personal networks on traditional sources (such as family) and are more likely to include voluntary sources, such as friends, coworkers and club members.

The aim of this paper is to propose a simple model that captures and explains these facts and analyze the consequences in the labor market.

To be more precise, we develop a model where each agent meet strong and weak ties that can help them find a job. ${ }^{3}$ We define a weak tie when the social interaction between two persons is transitory (like for example random encounters). On the contrary, a person has a strong-tie when the relationship is repeated over time, for example members of the same family or very close friends. ${ }^{4}$ Each individual can be in three different states: either she is unemployed and her strong tie is also unemployed or she is unemployed and her strong tie is employed (or the reverse) or both are employed. Workers move between the city and the rural area. In the city, the unemployed workers can find a job either directly or through weak and strong ties and the unemployed workers have to decide how much time (effort) to spend with weak ties. This depends on own effort, on agglomeration economics (since in denser areas, workers tend to meet more people) and on the competition in the labor market (the more employed workers live in the city, the easiest is to meet one of them; the same is true for the unemployed workers).

\footnotetext{
${ }^{1}$ This is the perspective of the so-called social disorganization theory and the social capital literature (see e.g. Wirth, 1938, Coleman, 1988, and Putman, 1993, 2001).

${ }^{2}$ This is the so-called subculture theory (see e.g. Fisher 1976, 1982).

${ }^{3}$ The fact that workers use their friends and relatives (social networks) to find a job is well-documented. See, e.g. Ioannides and Loury (2004).

${ }^{4}$ This is not the precise definition of weak ties first used by Granovetter. In Granovetter's (1973), weak ties are expressed in terms of lack of overlap in personal networks between any two agents; i.e. weak ties refer to a network of acquaintances who are less likely to be socially involved with one another. Formally, two agents A and B have a weak tie if there is little or no overlap between their respective personal networks. Vice versa, the tie is strong if most of A's contacts also appear in B's network.
} 
We show that, in denser areas (i.e. more populated areas like cities), individuals choose to interact with more people and meet more random encounters (weak ties) than in sparsely populated areas. Although those relationships may not be personal nor strong, yet those weak ties are the ones to matter most for providing social support, in particular in finding jobs. We also demonstrate that, for low urbanization levels, there is a unique steady-state equilibrium where workers do not interact with weak ties, while, for high level of urbanization, there is a unique steady-state equilibrium with full social interactions. We finally show that these equilibria are usually not socially efficient when the urban population has an intermediate size because there are too few social interactions compared to the social optimum. Even when social interactions are optimal, we show that there is over-urbanization in equilibrium.

The rest of the paper unfolds as follows. In the next section, we describe the relation to the literature. Section 3 describes the basic environment of the model while, in Section 4, we determine the steady-state equilibrium. In Section 5, we derive the comparative statics properties of our equilibrium and discuss the efficiency results in Section 6. Finally, Section 7 concludes the paper. All the proofs of the propositions can be found in the Appendix.

\section{Related literature}

Our paper contributes to the literature on "social interactions and cities", which is a small but growing field. There are, in fact, few papers that explicitly model both aspects.

Urban economics and economics of agglomeration There is an important literature in urban economics looking at how interactions between agents create agglomeration and city centers. $^{5}$ However, very few models have put forward the role of social interactions in the agglomeration process. Beckmann (1976) was among the first to propose an urban model with global social interactions. This model describes the urban structure of a single city and shows that, in equilibrium, agents are distributed according to a unimodal spatial distribution. More recently, Mossay and Picard $(2011,2013)$ propose interesting models in which each agent visits other agents so as to benefit from face-to-face communication (social interactions) and each trip involves a cost which is proportional to distance. The models provide an interesting discussion of spatial issues in terms of use of residential space and formation of neighborhoods and show under which condition different types of city structure emerge. Furthermore, Ghiglino and Nocco (2012) extend the standard economic geography model a la Krugman to incorporate conspicuous

\footnotetext{
${ }^{5}$ See Fujita and Thisse (2013) for a literature review.
} 
consumption. In their model, agents are sensitive to comparisons within their own type group as well as with agents that are outside their own type group. They show that agglomeration patterns depend on the network structure where agents are embedded in. All these models are different from ours since there is no labor market and weak and strong ties are not explicitly modeled.

Peer effects, social networks and urbanization There is a growing interest in theoretical models of peer effects and social networks (see e.g. Akerlof, 1997; Glaeser et al., 1996; Ballester et al., 2006; Calvó-Armengol et al., 2009). However, there are very few papers that explicitly consider the interaction between the social and the geographical space. ${ }^{6}$ Brueckner et al. (2002), Helsley and Strange (2007), Brueckner and Largey (2008) and Helsley and Zenou (2014) are exceptions but, in all these models either the labor market is not included or weak and strong ties are not modeled. Zenou (2013) is the only paper that has both aspects but the focus is totally different since the paper mainly explains the differences between blacks and whites in terms of labor market outcomes. ${ }^{7}$ Schelling (1971) is clearly a seminal reference when discussing social preferences and location. Shelling's model shows that, even a mild preference for interacting with people from the same community can lead to large differences in terms of location decision. Indeed, his results suggest that total segregation persists even if most of the population is tolerant about heterogeneous neighborhood composition. ${ }^{8}$ Our model is very different from models a la Schelling since we focus on weak and strong ties and their impact on labor-market outcomes.

To the best of our knowledge, our paper is the first one to provide a model that shows how urbanization affects social interactions. We show that workers interact more with their weak ties in more urbanized areas. Thus, the paper provides a first stab at a very important question in both social networks and urban economics.

\footnotetext{
${ }^{6}$ Recent empirical researches have shown that the link between these two spaces is quite strong, especially within community groups (see e.g. Bayer et al., 2008; Hellerstein et al., 2011; Ioannides and Topa, 2010; Patacchini and Zenou, 2012; Topa, 2001). See also Ioannides (2012, Chap. 5) who reviews the literature on social interactions and urban economics.

${ }^{7}$ See also Calvó-Armengol et al. (2007), Calvó-Armengol and Jackson (2004) and Zenou (2014) for models of weak and strong ties in the labor market but where the urban space is not modeled.

${ }^{8}$ This framework has been modified and extended in different directions, exploring, in particular, the stability and robustness of this extreme outcome (see, for example, Zhang, 2004 or Grauwin et al., 2012).
} 


\section{Basic environment}

The total size of the population is $N$. People can live either in the city, which population size is $N_{c}$, or in the rural area, with population size of $N_{r}$, with $N_{r}+N_{c}=N$.

\subsection{Dyads}

We assume that individuals belong to mutually exclusive two-person groups, referred to as dyads. We say that two individuals belonging to the same dyad hold a strong tie to each other. We assume that dyad members do not change over time. A strong tie is created once and for all and can never be broken. We can think, for example, of a married couple (or members from the same family) so that they tend to stay together for a long time.

Each individual can be in either of two different states: employed or unemployed. Dyads, which consist of paired individuals, can thus be in three different states,${ }^{9}$ which are the following:

(i) both members are employed - we denote the number of such dyads by $d_{2}$;

(ii) one member is employed and the other is unemployed $\left(d_{1}\right)$;

(iii) both members are unemployed $\left(d_{0}\right)$.

\subsection{Aggregate state}

By denoting the employment level and the unemployment level in the city at time $t$ by $E_{c}(t)$ and $U_{c}(t)$, we have:

$$
\left\{\begin{array}{l}
E_{c}(t)=2 d_{2}(t)+d_{1}(t) \\
U_{c}(t)=2 d_{0}(t)+d_{1}(t)
\end{array}\right.
$$

Since the total urban population is $N_{c}$, we have

$$
E_{c}(t)+U_{c}(t)=N_{c}
$$

or, alternatively,

$$
d_{2}(t)+d_{1}(t)+d_{0}(t)=\frac{N_{c}}{2}
$$

\subsection{Rural versus urban areas}

We assume that only people belonging to a $d_{0}$ dyad can freely choose where to live between the urban and the rural area. The other people, belonging either to a $d_{1}$ or $d_{2}$ dyad, who are mostly

\footnotetext{
${ }^{9}$ The inner ordering of dyad members does not matter.
} 
employed, stay for ever in the city $c$. This is because workers in a $d_{0}$ dyad are all unemployed and thus are ready to move to improve their utility. On the contrary, workers from the other dyads, who are mostly employed, will not find it optimal to move to the rural area. We can easily show that this is optimal in equilibrium.

\subsection{Labor market}

The rural labor market is perfectly competitive and has no friction. In other words, everybody can obtain a job in the rural area and it is assumed that the rural wage is flexible enough to guarantee that there is full-employment. ${ }^{10}$ The wage in the rural area $w_{r}$ is thus determined by the marginal productivity of workers, i.e.

$$
w_{r}=f^{\prime}\left(N-N_{c}\right)
$$

As usual, we assume that $f^{\prime}()>$.0 and $f^{\prime \prime}() \leq$.0 and that the Inada conditions hold. These assumptions reflect the implicit assumption that the land endowment is limited and the agricultural sector exhibits decreasing returns with respect to labor input.

\subsection{Information transmission in the city}

The labor market in the city is not perfectly competitive because, for example, of search frictions. Let us now describe the information transmission about jobs in the city.

Each job offer is taken to arrive to both employed and unemployed workers at rate $\lambda$. If an employed worker hears about a job, she automatically direct it to her strong tie. This is a convenient modelling assumption, which stresses the importance of on-the-job information (Ioannides and Loury, 2004). All jobs and all workers are identical (unskilled labor) so that all employed workers obtain the same wage $w_{c}$. Therefore, the employed workers, who hear about a job, pass this information on to their current matched partner since they cannot use this information for themselves. They can also transmit this job information to a weak tie if they meet one.

As stated above, we assume that only members of a $d_{0}$ dyad can migrate. Since they are newcomers in the city relatively to other dyad members, an unemployed worker in a $d_{0}$ dyad is assumed to have no social connections, i.e. no contact with weak ties. This is because it takes

\footnotetext{
${ }^{10}$ This is a standard assumption in the migration literature (see e.g. Zenou, 2011) and it does make sense, especially in developing countries, where jobs in rural areas are mostly from the agricultural sector and easy to obtain. Also many rural firms are family related and thus coordination failures and thus search frictions should not be too large (see e.g. Yamada, 1996; Marcouiller et al., 1997; Maloney, 1999).
} 
time to meet weak ties and people who are stuck in a $d_{0}$ dyad tend to interact mostly with their strong ties and isolate themselves from the urban community. As a result, the only way they can find a job is by hearing directly about it at rate $\lambda$. On the contrary, an unemployed worker in a $d_{1}$ dyad can meet weak ties and obtain job information from them. We denote by $\gamma \in[0, \bar{\gamma}]$ the effort of interacting with weak ties for an unemployed worker in a $d_{1}$ dyad. There is an effort cost, which is given by $c \gamma(c>0)$. We also assume that there are agglomeration effects so that the higher is the urban population $N_{c}$, the easier is to meet weak ties (see, e.g. Desmond, 2012 , for evidence). The agglomeration effect is captured by $\phi\left(N_{c}(t)\right)$, with $\phi^{\prime}()>0,. \phi^{\prime \prime} \leq 0$ and $0<\underline{\phi} \leq \phi(\cdot) \leq \bar{\phi} \leq 1$.

As a result, an unemployed worker in a $d_{1}$ dyad will hear about a job from a weak tie at rate $\gamma \phi\left(N_{c}(t)\right) 2 \lambda d_{2}(t) / d_{1}(t)$. Indeed, the rate at which an unemployed worker obtains a job from a weak tie is increasing in her own effort $\gamma$, in the urban population $N_{c}(t)$ and depends on $2 \lambda d_{2}(t) / d_{1}(t)$, the fraction of employed workers who are aware about a job. In other words, $2 \lambda d_{2}(t) / d_{1}(t)$ captures something similar to the matching function in the search literature (Pissarides, 2000) where the number of employed workers in the $d_{2}$ dyad is $2 d_{2}(t)$ while the number of unemployed workers who are in competition for job information is $d_{1}(t)$. Hence, an unemployed worker in a $d_{1}$ dyad can find a job either directly at rate $\lambda$ or through her strong tie at rate $\lambda$ or through her weak tie at rate $\gamma \phi\left(N_{c}(t)\right) 2 \lambda d_{2}(t) / d_{1}(t)$. Letting $g(t)$ be the rate at which an unemployed worker in a $d_{1}$ dyad finds a job (or equivalently the rate at which a $d_{1}$ dyad becomes a $d_{2}$ dyad), we have

$$
g(t) \equiv 2 \lambda+\gamma \phi\left(N_{c}(t)\right) 2 \lambda \frac{d_{2}(t)}{d_{1}(t)}
$$

Finally, we assume that each dyad "dies" at rate $\delta$. If we think of the married couple interpretation of a dyad, this means that the couple in the dyad retires and leave the economy. In that case, they are replaced by a new $d_{0}$ dyad. For example, if a $d_{1}$ dyad "dies", then a new $d_{0}$ dyad will be created. The rational for this is that a new dyad is composed of young workers who have not worked yet. This is an overlapping generation model. As a result, at each period of time $t, \delta\left[d_{2}(t)+d_{1}(t)+d_{0}(t)\right]$ die and $\delta\left[d_{2}(t)+d_{1}(t)+d_{0}(t)\right]=\delta N_{c}(t) / 2$ are born as a $d_{0}$ dyad. Observe that $\lambda$, the rate at which a person hears from a job, is individual specific while $\delta$, the rate at which a dyad dies, is dyad specific.

This information transmission protocol defines a continuous time Markov process. The state variable is the relative size of each type of dyad. Transitions depend on labor market turnover and the nature of social interactions as captured by $\gamma$. Because of the continuous time Markov process, the probability of a two-state change is zero (small order) during a small interval of 
time $t$ and $t+d t$. This means, in particular, that both members of a dyad cannot change their status at the same time. For example, two unemployed workers cannot find a job at the same time, i.e. during $t$ and $t+d t$, the probability assigned to a transition from a $d_{0}-$ dyad to a $d_{2}-$ dyad is zero. Similarly, two employed workers $\left(d_{2}-\right.$ dyad) cannot both become unemployed, i.e. switch to a $d_{0}-$ dyad during $t$ and $t+d t$. This applies to all other dyads mentioned above.

\subsection{Flows of dyads between states}

It is readily checked that the net flow of dyads from each state between a small interval of time $t$ and $t+d t$ is given by:

$$
\left\{\begin{array}{l}
\dot{d}_{2}(t)=g(t) d_{1}(t)-\delta d_{2}(t) \\
\dot{d}_{1}(t)=2 \lambda d_{0}(t)-[\delta+g(t)] d_{1}(t) \\
\dot{d}_{0}(t)=\frac{\delta N_{c}(t)}{2}-2 \lambda d_{0}(t)-\delta d_{0}(t)+\frac{1}{2} N_{c}(t)
\end{array}\right.
$$

where $g(t)$ is defined by (5) and

$$
\dot{N}_{c}(t)=\alpha\left[W_{0 c}^{u}(t)-\Omega\right]
$$

where $W_{0 c}^{u}(t)$ is the lifetime expected utility of an unemployed worker in a $d_{0}$ dyad living in the city, $\Omega$ is lifetime expected utility of a rural worker and $\alpha>0$ is a parameter. As stated above, all rural workers who migrate to the city start as unemployed in a $d_{0}$ dyad. Because people in the same dyad are married (or family members), the migration decision is always made together (within the dyad) and not individually. In other words, it is not possible for two persons from the same dyad to live in different areas.

Let us explain (6). The positive change of $d_{0}$ dyads over time is due to the fact that, at each period of time $t, \delta\left[d_{2}(t)+d_{1}(t)+d_{0}(t)\right]$ die and $\delta\left[d_{2}(t)+d_{1}(t)+d_{0}(t)\right]=\delta N_{c}(t) / 2$ are born as

a $d_{0}$ dyad and that $\frac{1}{2} N_{c}(t)$ workers migrate to the city in a $d_{0}$ dyad. The negative change of $d_{0}$ dyads over time is due to the fact that one of the workers from a $d_{0}$ dyad finds a job directly $(2 \lambda)$ and that the dyad dies $(\delta)$. For $d_{1}$ dyads, they increase their size because one of the workers from a $d_{0}$ dyad got a job directly $(2 \lambda)$ but they lose people because either the dyad died $(\delta)$ or because the unemployed worker from the $d_{1}$ dyad obtained a job $(g(t))$. Finally, for $d_{2}$ dyads, they gain people from $d_{1}$ dyads $(g)$ but lose people since the dyad can die at rate $\delta$.

Remember that the number of employed workers in the city, $E_{c}(t)$, is given by $E_{c}(t)=$ $2 d_{2}(t)+d_{1}(t)$ whereas the number of unemployed workers, $U_{c}(t)$, is given by $U_{c}(t)=2 d_{0}(t)+d_{1}(t)$. As a result, $N_{c}(t)=E_{c}(t)+U(t)=2\left[d_{0}(t)+d_{1}(t)+d_{2}(t)\right]$. In steady state, $\dot{d}_{2}(t)=0, \dot{d}_{1}(t)=0$, 
$\dot{d}_{0}(t)=0$ and $\dot{N}_{c}(t)=0$, and the flows in the labor market can be described by the following figure:

$$
\text { [Insert Figure } 1 \text { here] }
$$

By solving (6) in steady state, we obtain:

$$
\begin{gathered}
d_{0}^{*}=\frac{\delta N_{c}^{*}}{2(\delta+2 \lambda)} \\
d_{1}^{*}=d_{2}^{*}\left[\frac{\delta}{2 \lambda}-\gamma \phi\left(N_{c}^{*}\right)\right] \\
d_{2}^{*}=\frac{2 \lambda^{2} N_{c}^{*}}{(\delta+2 \lambda)\left[\delta+2 \lambda\left(1-\gamma \phi\left(N_{c}^{*}\right)\right)\right]}
\end{gathered}
$$

For $d_{1}^{*}$ to be strictly positive, we assume that

$$
2 \lambda \bar{\phi} \bar{\gamma}<\delta
$$

Moreover, for $d_{2}^{*}$ to be positive, we assume that $\delta+2 \lambda(1-\bar{\gamma} \bar{\phi})>0$, which can be rearranged as

$$
2 \lambda \bar{\phi} \bar{\gamma}<\delta+2 \lambda
$$

Combining (11) and (12) leads to

$$
2 \lambda \bar{\phi} \bar{\gamma}<\delta
$$

\subsection{Steady-state asset value equations}

Let us write the steady-state lifetime expected utilities of all workers (i.e. the Bellman equations). For a rural worker, we have:

$$
r \Omega=w_{r}-\delta \Omega
$$

where $\Omega$ is lifetime expected utility of a rural worker, $w_{r}$ is the rural wage defined by (4), and $r$ is the discount rate. Observe that, in rural areas, people live in family within a dyad. As in the urban area, a dyad that dies (at rate $\delta$ ) is automatically replaced by a new dyad (but a $d_{2}$ dyad since there is full employment). As a result, in rural areas, all workers are in a $d_{2}$ dyad (forever). When they migrate to the city, they switch from a $d_{2}$ dyad from the rural area to a $d_{0}$ dyad in the city.

Let us now write $W_{c}^{e}$, the lifetime expected utility of an urban worker who is employed in the city. It is given by:

$$
r W_{c}^{e}=w_{c}-\delta W_{c}^{e}
$$


where $w_{c}$ is the (exogenous) urban wage. Observe that being employed does not depend on which dyad you belong to. This is because, in this model, people are employed for ever until they exist the economy (at rate $\delta$ ) either because they retire or they die. ${ }^{11}$ This is, however, not true for the unemployed workers because their chance of escaping unemployment depends on which dyad they belong to. Denote by $W_{0 c}^{u}$, the lifetime expected utility of an urban unemployed worker in a $d_{0}$ dyad. Then, we have:

$$
r W_{0 c}^{u}=b+\lambda\left(W_{c}^{e}-W_{0 c}^{u}\right)+\lambda\left(W_{1 c}^{u}-W_{0 c}^{u}\right)-\delta W_{0 c}^{u}
$$

Indeed, when someone is unemployed in a $d_{0}$ dyad, she obtains an unemployment benefit of $0<b<w_{c}$. Then, she can hear directly about a job at rate $\lambda$ and become employed and thus obtains a surplus of $W_{c}^{e}-W_{0 c}^{u}>0$ or her partner in the dyad, who is also unemployed, finds a job at rate $\lambda$, and thus switches to a $d_{1}$ dyad so that the surplus is now $W_{1 c}^{u}-W_{0 c}^{u}>0$. Finally, the dyad can die at rate $\delta$ and the negative surplus is $0-W_{0 c}^{u}<0$.

Finally, the lifetime expected utility of an urban unemployed worker in a $d_{1}$ dyad is equal to:

$$
r W_{1 c}^{u}=b-\beta \gamma+g^{*}\left(W_{c}^{e}-W_{1 c}^{u}\right)-\delta W_{1 c}^{u}
$$

where $g^{*}$ is the steady-state rate at which the unemployed worker from a $d_{1}$ dyad finds a job and is equal to: ${ }^{12}$

$$
g^{*}=2 \lambda+\gamma \phi\left(N_{c}^{*}\right) 2 \lambda \frac{d_{2}^{*}}{d_{1}^{*}}
$$

Indeed, an unemployed worker in a $d_{1}$ dyad earns an unemployment benefit of $b$ and pays a cost of $\beta \gamma$ for interacting with weak ties in the city where $\beta>0$ is the marginal cost (remember that $\gamma$ is the worker's effort). This worker can leave unemployment at rate $g^{*}$ and obtain a surplus of $W_{c}^{e}-W_{1 c}^{u}>0$ or the dyad can die at rate $\delta$. We assume that $\bar{\gamma} \leq b / \beta$, which ensures that $b-\beta \gamma \geq 0$. Since $b / \beta$ is the natural upper bound of $\gamma$, we set $\bar{\gamma}=b / \beta$ without loss of generality. As a result, condition (13) can be written as:

$$
2 \lambda \bar{\phi} \frac{b}{\beta}<\delta
$$

Solving for the Bellman equations, we easily obtain

$$
W_{0 c}^{u}=\frac{b+\lambda\left(W_{c}^{e}+W_{1 c}^{u}\right)}{r+\delta+2 \lambda}
$$

\footnotetext{
${ }^{11}$ This is clearly a simplified assumption, which helps us solve the model. If we relax it, the Bellman equations will become much more complicated and the resolution of the model more cumbersome but the results will be qualitatively unchanged.

${ }^{12} \mathrm{~A}$ variable with a star indicates that it is a steady-state equilibrium variable.
} 


$$
\begin{gathered}
W_{1 c}^{u}=\frac{b-\beta \gamma+\frac{g^{*} w_{c}}{r+\delta}}{r+\delta+g^{*}} \\
W_{c}^{e}=\frac{w_{c}}{r+\delta} \\
\Omega=\frac{w_{r}}{r+\delta}
\end{gathered}
$$

\section{Steady-state equilibrium}

\subsection{Definition}

Definition 1 A steady-state equilibrium $\left(N_{c}^{*}, \gamma^{*}\right)$ is such that the equilibrium migration condition is satisfied $\dot{N}_{c}(t)=0$, i.e.

$$
W_{0 c}^{u}=\Omega
$$

which determines $N_{c}^{*}$, and the unemployed workers in a $d_{1}^{*}$ dyad optimally choose $\gamma$ that maximizes $W_{1 c}^{u}$.

\subsection{Optimal choice of social interactions}

Let us determine the optimal $\gamma$. Unemployed workers in a $d_{1}^{*}$ dyad choose $\gamma$ that maximizes $W_{1 c}^{u}$, taking as given $N_{c}^{*}, d_{1}^{*}$ and $d_{2}^{*}$. Define

$$
\underline{N}_{c} \equiv \phi^{-1}\left(\frac{\delta \beta(r+\delta+2 \lambda)}{4 \lambda^{2}\left(w_{c}-b\right)+2 \lambda \bar{\gamma} \beta(r+\delta+2 \lambda)}\right)
$$

We have the following result:

Proposition 1 Assume (19).

(i) If the city population is sufficiently small, i.e. $N_{c}<\underline{N}_{c}$, then unemployed workers in a $d_{1}^{*}$ dyad choose not to interact with weak ties, i.e. $\gamma^{*}=0$.

(ii) If the city population is sufficiently large, i.e. $N_{c} \geq \underline{N}_{c}$, then unemployed workers choose to fully interact with weak ties, i.e. $\gamma^{*}=\bar{\gamma}$.

This is an interesting result that links urban population to social interactions. The intuition of this result is as follows. When choosing their optimal social-interaction effort $\gamma$, workers trade off the long-run benefits of increasing $\gamma$, which is finding a job more quickly, and the short-run costs, which is simply the effort cost $\beta \gamma$. Moreover, the benefits from increasing $\gamma$ is captured by $g^{*}$, the rate at which the workers leave unemployment, which increases with $\gamma$ but depends 
on the size of the urban population $N_{c}$ (agglomeration effect). When this population size is too small, the benefits are lower than the costs and workers are better off not interacting with weak ties and only relying on direct methods and their strong ties. When urbanization increases above a certain population size, the benefits outweigh the costs and it becomes optimal for workers to fully interact with weak ties. Observe that $\underline{N}_{c}$ depends on the different parameters of the model. Since $\phi($.$) is an increasing function, it can be seen that \underline{N}_{c}$ is decreasing with $w_{C}$ and $\lambda$ and increasing with $b, \beta, \delta$. Take, for example, $\lambda$ and $\delta$. The higher is $\lambda$ (or the lower is $\delta$ ), the lower is $\underline{N}_{c}$ and the less likely the unemployed workers will choose $\gamma=0$. This is because the returns from increasing $\gamma$ are higher while the cost is unaffected. The same intuition runs for $w_{C}-b$.

Let us now discuss the main result of our proposition, which is that social interactions increase with urbanization. As stated in the Introduction, there is a literature in sociology that supports this result (see e.g. Wirth, 1938, Coleman, 1988, and Putman, 1993, 2001). ${ }^{13}$ Let us review in more detail this literature. Fisher (1982) found that urban dwellers had more dispersed networks containing a higher proportion of non-kin relations than did rural dwellers. This concurs with Wellman's (1979) research in a number of Toronto neighborhoods demonstrating that personal networks are geographically dispersed with large variations in the number of contacts living in the neighborhood. In a review of different studies in the US, Korte (1980) concluded that urbanism positively affects only those relationships which are peripheral; central relationships including ties between families and friends, remained unchanged. Palisi and Canning (1986) found that urbanism was positively associated with the frequency of interaction among friends.

However, although individuals may have fewer strong relationships in cities than in villages, they have more random encounters (weak ties), which are more important for support. As Granovetter's (1973) seminal work on the strength of the weak ties argues, weak ties are superior to strong ties for providing support in getting a job. He criticized the assumption that strong ties in close networks were strong in resource terms. Using the example of searching for a job, Granovetter found that neighborhood based close networks were limited in getting information about possible jobs (see also Lin and Dumin 1986). In a close networks everyone knows each other, information is shared and so potential sources of information are quickly shaken down, the networks quickly becomes redundant in terms of access to new information. In contrast Granovetter stresses the strength of weak ties involving a secondary ring of acquaintances who

\footnotetext{
${ }^{13}$ This, in fact, goes back to Tonnies (1957) and Simmel (1995) with the idea of rural gemeinschaft (or community) and urban gesellchaft (or association).
} 
have contacts with networks outside ego's network and therefore offer new sources of information on job opportunities. The network arrangements in play here involve only partially overlapping networks composed mainly of single-stranded ties. Amato (1993) examines the differences between urban and rural dwellers, as well as between large cities and smaller towns inhabitants, in the breadth of assistance received and provided by friends and family. He finds that urbanites receive more help from friends than do rural dwellers, give more help to friends, expect more help from friends, and expect less help from relatives. In other words, he finds little support for the social disorganization theory that argues that urban dwellers receive and provide less support from friends and relatives compared to rural people. In a study on the relationships between health outcomes and social networks in several east London neighborhoods, Cattell (2001) concluded that the most robust networks in terms of health outcomes are those Solidarity Networks that combine positive aspects of dense and loose networks. They consist of a wide range of membership groups, made up of similar and dissimilar people involving strong local contacts of family or local friends and neighbors on the one hand, plus participation in formal and informal organizations on the other. As Cattell concludes "the more varied the network, the greater the range of resources accessible, and the greater the potential benefits to health." (Cattell 2001: 1513).

In economics, there are few papers testing this type of relationship. Wahba and Zenou (2005) is an exception and they find that, in Egypt, in denser cities, people are more likely to find a job through weak ties than in less dense cities.

\subsection{Characterization of equilibrium}

Equation (20) implies that the asset value of an unemployed worker in the $d_{0}$ dyad, $W_{0 c}^{u}$, increases with $W_{1 c}^{u}$. Because $W_{c}^{e}$ does not depend on $\gamma$, we know that $\left.W_{0 c}^{u}\right|_{\gamma=\bar{\gamma}}$ is larger than $\left.W_{0 c}^{u}\right|_{\gamma=0}$ if and only if $\left.W_{1 c}^{u}\right|_{\gamma=\bar{\gamma}}$ is larger than $\left.W_{1 c}^{u}\right|_{\gamma=0}$, i.e., the city population is sufficiently large so that $N_{c}>\underline{N}_{c}$.

Definition 2 A No-Interaction Equilibrium $\left(N_{c}^{N I *}, \gamma^{N I *}\right)$ is when all workers in the city choose $\gamma^{N I *}=0$ while a Full-Interaction Equilibrium $\left(N_{c}^{F I *}, \gamma^{F I *}\right)$ is when all workers in the city choose $\gamma^{F I *}=\bar{\gamma}$

The city population is determined by the decision of the new entrants to migrate to the city. This requires that the asset value of a rural employed worker to be equal to that of an urban unemployed worker in the $d_{0}$ dyad, i.e. $\Omega=W_{0 c}^{u}$. The following proposition characterizes the 
equilibrium.

Proposition 2 Assume (19).

(i) If $N_{c}<\underline{N}_{c}$, then there exists a No-Interaction Equilibrium $\left(N_{c}^{N I *}, \gamma^{N I *}\right)$ such that all urban workers provide effort $\gamma^{N I *}=0$.

(ii) If $N_{c} \geq \underline{N}_{c}$, then there exists a Full-Interaction Equilibrium $\left(N_{c}^{F I *}, \gamma^{F I *}\right)$ such that all urban workers exert effort $\gamma^{F *}=\bar{\gamma}$.

In the proof of Proposition 2, we provide, for each equilibrium, the equilibrium values of the numbers of dyads, $d_{0}^{*}, d_{1}^{*}$ and $d_{2}^{*}$, the equilibrium urban population size $N_{c}^{*}$, the level of urban unemployment $U_{c}^{*}$, the job arrival rate of an unemployed worker in a $d_{1}$ dyad, $g^{*}$, and all the equilibrium value functions for all workers. This proposition confirms our previous result showing how urbanization (capture by $N_{c}$ ) affects the social behavior of workers.

\subsection{Existence and uniqueness of equilibrium}

Since, in Proposition 2, the condition for equilibrium depends on $N_{c}$, an endogenous variable, we need to examine under which condition there exists an equilibrium and if it is unique. The determination of the city population $N_{c}$ is described in Figure 2(a) and Figure 2(b).

\section{[Insert Figures 2(a) and 2(b) here]}

In Figure 2(a), the horizontal axis represents the urban population $N_{c}$ from the right. The rural population $N_{r}$ is represented by the difference between $N$ and $N_{c}$. The vertical axis shows the asset values $\Omega$ and $W_{0 c}^{u}$. $\Omega$ is represented by a upward sloping curve (with respect to the urban population $N_{c}$ ) because $d \Omega / d N_{c}=-d \Omega / d N_{r}=-f^{\prime \prime} /(r+\delta)>0$. From (32), (33) and (35), we know that $\left.W_{0 c}^{u}\right|_{\gamma=0}$ is independent of $N_{c}$ whereas $\left.W_{0 c}^{u}\right|_{\gamma=\bar{\gamma}}$ is increasing in $N_{c}$. Observe first that $\Omega$ and $\left.W_{0 c}^{u}\right|_{\gamma=0}$ has a unique interaction if $\left.W_{0 c}^{u}\right|_{\gamma=0}>f^{\prime}(N) /(r+\delta)$ because we assumed the Inada conditions for $f(\cdot)$. Observe second that $\left.W_{0 c}^{u}\right|_{\gamma=\bar{\gamma}}>\left.W_{0 c}^{u}\right|_{\gamma=0}$ as long as Figure 2(b) is relevant. The Inada condition for $f(\cdot)$ combined with the fact that $\left.W_{0 c}^{u}\right|_{\gamma=\bar{\gamma}, \phi=\phi(N)}$ has a finite value, ensures that $\Omega$ and $\left.W_{0 c}^{u}\right|_{\gamma=\bar{\gamma}}$ has at least one intersection.

In Figure 2(a), when the total population $N$ increases, the urban population, $N_{c}$, also increases. This can be confirmed by totally differentiating $\Omega=\left.W_{0 c}^{u}\right|_{\gamma=0}$ since we have: $d N_{c} / d N=$ $1>0$. When the city population reaches $\widehat{N}_{c}$, the regime switches from the no-social interaction case $\left(\gamma^{*}=0\right)$ to the full social interaction case $\left(\gamma^{*}=\bar{\gamma}\right)$ and the equilibrium population distribution is determined by $\Omega=\left.W_{0 c}^{u}\right|_{\gamma=\bar{\gamma}}$. We have the following proposition: 
Proposition 3 Assume (19).

(i) If $N_{c}^{*}$ is small enough, i.e. $N_{c}^{*}<\underline{N}_{c}$, then the city is characterized by no social interaction $\left(\gamma^{*}=0\right)$ and there is therefore a No-Interaction Equilibrium $\left(N_{c}^{N I *}, \gamma^{N I *}\right)$. Furthermore, if Condition (52) holds, then the No-Interaction Equilibrium $\left(N_{c}^{N I *}, \gamma^{N I *}\right)$ is unique and given by (37)-(38) (see Figure 2(a)).

(ii) If $N_{c}^{*}$ is large enough, i.e. $N_{c}^{*}>\underline{N}_{c}$, then the city is characterized by full social interactions $\left(\gamma^{*}=\bar{\gamma}\right)$ and there is therefore a Full-Interaction Equilibrium $\left(N_{c}^{F I *}, \gamma^{F I *}\right)$. Furthermore, if Conditions (52) and (53) hold, then the Full-Interaction Equilibrium $\left(N_{c}^{F I *}, \gamma^{F I *}\right)$ is unique and given by (45)-(47) (see Figure 2(b)).

When the level of urbanization is low, the contact rate with weak ties, $\phi\left(N_{c}\right)$, is also low so that it is not worth devoting much effort to interact with weak ties. As the urban population grows, the agglomeration effect regarding the contact rate gets larger and it becomes rewarding to social interact with weak ties. As will be shown in the next section, the urban population size, $N_{c}^{*}$, increases with the total population size (rural plus urban), $N$, in the No-Interaction equilibrium. Moreover, $N_{c}^{*}$, determined by (44), has the property that $\lim _{N \rightarrow \infty} N_{c}^{*}=\infty$. Hence, there exists a threshold value of $N$ under which we observe the No-Interaction equilibrium and beyond which we observe the Full-Interaction equilibrium. Thus, if we consider a continuous growth process of total population size, there will be a regime change from the No-Interaction equilibrium to the Full-Interaction equilibrium in the city.

\section{Comparative statics}

In this section, we provide the results of basic comparative statics with respect to the urban population size, $N_{c}^{*}$, and the unemployment rate, $u_{c}^{*}=U^{*} / N$.

\section{$5.1 \quad$ No-Interaction Equilibrium}

Let us start with the No-Interaction equilibrium $\left(N_{c}^{N I *}, \gamma^{N I *}\right)$, where $N_{c}^{*}$ is determined by (44) and is described in Figure 2(a). In order to focus on the unique No-Interaction equilibrium, we assume that condition (52) holds. We provide here explanations based on the figure and relegate the formal proofs to the Appendix. As shown in Figure 2(a), an increase in the urban wage, $w_{c}$, in the unemployment benefit, $b$, or in the direct job arrival rate, $\lambda$, raises the asset value of an urban unemployed worker in a $d_{0}$ dyad, $\left.W_{0 c}^{u}\right|_{\gamma=0}$, whereas it doesn't affect the asset value of a 
rural employed worker, $\Omega$. Hence, by increasing these variables, cities will attract more people and the urban population size, $N_{c}^{*}$, will become larger. Furthermore, an increase in the exit rate, $\delta$, or the discount rate, $r$, lowers the asset values, but the reduction is larger for an urban unemployed worker. As a result, $N_{c}^{*}$, decreases. An increase in the total population, size $N$, reduces $\Omega$, leading to a larger $N_{c}^{*}$.

The effects on unemployment rate can be readily examined. Because the number of unemployed workers is given by (38), the effect of an increase of $w_{c}, b$, or $r$ on the unemployment rate, $u_{c}^{*}=U^{*} / N$, is proportional to that of $N_{c}^{*}$. An increase in $N$ affects both the numerator, $U^{*}$, and the denominator, $N$, of $u_{c}^{*}=U^{*} / N$. Still, we can see from the Appendix that $\partial N_{c}^{*} / \partial N=1$, implying that $\partial\left(N_{c}^{*} / N\right) / \partial N=\left(N-N_{c}^{*}\right) / N^{2}>0$. Hence, we know that an increase in $N$ raises $u_{c}^{*}$. However, an increase in $\delta$ or $\lambda$ has additional impacts on $u_{c}^{*}$, making its total effect on unemployment rate ambiguous. The following proposition summarizes our findings:

Proposition 4 Suppose that Condition (52) holds. In the No-Interaction equilibrium $\left(N_{c}^{N I *}, \gamma^{N I *}\right)$, an increase in $w_{c}, b, N$, or $\lambda$, or a decrease in $\delta$ or $r$ increases the urban population size, $N_{c}^{*}$. Moreover, an increase in $w_{c}, b$, or $N$, or a decrease in $r$ increases the unemployment rate, $u_{c}^{*}$. An increase in $\delta$ or $\lambda$ has an ambiguous effect on $u_{c}^{*}$.

\subsection{Full-Interaction Equilibrium}

We next examine the Full-interaction equilibrium, where the urban population size is determined by (51) and is described in Figure 2(b). Here, we assume that conditions (52) and (53) hold so that the model has the unique Full-Interaction equilibrium $\left(N_{c}^{F I *}, \gamma^{F I *}\right)$. As shown in Figure 2(b), a higher value of $w_{c}$ shifts the asset value of an urban unemployed worker in a $d_{0}$ dyad, $\left.W_{0 c}^{u}\right|_{\gamma=\bar{\gamma}}$, upwards whereas it doesn't change the asset value of a rural employed worker, $\Omega$. Thus, it increases $N_{c}^{*}$. Furthermore, an increase in $N$ lowers $\Omega$ whereas it doesn't change $\left.W_{0 c}^{u}\right|_{\gamma=\bar{\gamma}}$, resulting in a larger $N_{c}^{*}$. Unfortunately, the effects of a change in other parameters are ambiguous.

The effects of unemployment rate, $u_{c}^{*}$, are somewhat more complicated in this case because now the urban population size (and hence density) has agglomeration effects on the contact rate with weak ties described by $\phi\left(N_{c}\right)$. From (47), we can see that, on the one hand, a larger $N_{c}^{*}$ has an direct effect of raising $u_{c}^{*}$. On the other hand, it indirectly lowers $u_{c}^{*}$ by raising $\phi\left(N_{c}\right)$. Such an indirect effect is not sufficient to dominate the direct effect in the case of an increase in $w_{c}$, but it is so in the case of an increase in $N$. 
Proposition 5 Suppose that conditions (52) and (53) hold. In the Full-Interaction equilibrium $\left(N_{c}^{F I *}, \gamma^{F I *}\right)$, an increase in $w_{c}$ or $N$ increases the urban population size, $N_{c}^{*}$. Moreover, an increase in $w_{c}$ increases the unemployment rate, $u_{c}^{*}$, whereas an increase in $N$ decreases it. An increase in $b, \delta, \lambda$, or $r$ has ambiguous effects on $N_{c}^{*}$ and $u_{c}^{*}$.

The following table summarizes all our comparative statics results:

\begin{tabular}{|c|c|c|c|c|c|c|}
\hline \multicolumn{7}{|c|}{ No-Interaction equilibrium $\left(\gamma^{*}=0\right)$} \\
\hline & $w_{c}$ & $b$ & $N$ & $\delta$ & $\lambda$ & $r$ \\
\hline$N_{c}^{*}$ & + & + & + & - & + & - \\
\hline$u_{c}^{*}$ & + & + & + & $?$ & $?$ & - \\
\hline \multicolumn{7}{|c|}{ Full-Interaction equilibrium $\left(\gamma^{*}=\bar{\gamma}\right)$} \\
\hline & $w_{c}$ & $b$ & $N$ & $\delta$ & $\lambda$ & $r$ \\
\hline$N_{c}^{*}$ & + & $?$ & + & $?$ & $?$ & $?$ \\
\hline$u_{c}^{*}$ & + & $?$ & - & $?$ & $?$ & $?$ \\
\hline
\end{tabular}

Table 1: Comparative statics for both equilibria

\section{Efficiency}

In this section, we explore the efficiency properties of each equilibrium. Our questions are as follows: $(i)$ are the decisions in terms of social interactions, $\gamma^{*}$, efficient? and $(i i)$ is the degree of urbanization, $N_{c}^{*}$, efficient? We follow the search and matching literature (Pissarides, 2000) by defining the social welfare, $S W$, as the sum of utilities of all workers, i.e.

$$
S W=\int_{0}^{\infty} e^{-r t}\left[f\left(N-N_{c}(t)\right)+E_{c}(t) w_{c}+U_{c}(t) b-\beta d_{1}(t) \gamma(t)\right] d t
$$

The dynamics of the number of dyads are given by (6). Note that

$$
\begin{aligned}
& E_{c}(t)=2 d_{2}(t)+d_{1}(t) \\
& U_{c}(t)=2 d_{0}(t)+d_{1}(t)
\end{aligned}
$$

and

$$
N_{c}(t)=2\left[d_{0}(t)+d_{1}(t)+d_{2}(t)\right]
$$


The planner chooses $\gamma(t)$ and $N_{c}(t)$ that maximize (26) under the flow constraint (6). We obtain the present-value Hamiltonian:

$$
\begin{aligned}
H_{t}=e^{-r t} & \left\{f\left(N-N_{c}(t)\right)+E_{c}(t) w_{c}+U_{c}(t) b-\beta d_{1}(t) \gamma(t)\right\} \\
& +\mu_{1}(t)\left[2 \lambda d_{0}(t)-(\delta+g(t)) d_{1}(t)\right]+\mu_{2}(t)\left[g(t) d_{1}(t)-\delta d_{2}(t)\right]
\end{aligned}
$$

where $\mu_{1}(t)$ and $\mu_{2}(t)$ are the Lagrangian multipliers (or co-state variables) corresponding to $\dot{d}_{1}(t)$ and $\dot{d}_{2}(t)$. We don't need to write the constraint corresponding to $\dot{d}_{0}(t)$ because we use (29). The control variables of the social planner are $\gamma(t)$ and $N_{c}(t)$ and the state variables are $d_{1}(t)$ and $d_{2}(t)$. We have the following result:

Proposition 6 When the urban population is sufficiently small $\left(N_{c} \leq \underline{N}_{c}^{o}\right)$, there is no social interactions in equilibrium and it is optimal from a social welfare viewpoint, i.e. $\gamma^{*}=\gamma^{o}=0$. When the urban population is sufficiently large $\left(N_{c}>\underline{N}_{c}^{*}\right)$, there is full social interactions in equilibrium and it is optimal from a social welfare viewpoint, i.e. $\gamma^{*}=\gamma^{o}=\bar{\gamma}$. When the urban population takes intermediate values $\left(\underline{N}_{c}^{o}<N_{c} \leq \underline{N}_{c}^{*}\right)$, there is no social interaction in equilibrium $\left(\gamma^{*}=0\right)$ while full social interactions are optimal $\left(\gamma^{o}=\bar{\gamma}\right)$.

Define $\widehat{\phi}^{o}$ as

$$
\widehat{\phi}^{o} \equiv \frac{\beta \delta(\delta+2 \lambda)}{2 \lambda\left(b \delta+2 w_{c} \lambda\right)} .
$$

As shown in the proof of Proposition 6, $\gamma=\bar{\gamma}$ is optimal if $\phi>\widehat{\phi}^{o}$ and $\gamma=0$ is optimal if $\phi<\widehat{\phi}^{o}$. Define next $\underline{N}_{c}^{o}$ as

$$
\underline{N}_{c}^{o} \equiv \phi^{-1}\left(\widehat{\phi}^{o}\right)
$$

Then, we obtain that $\gamma=\bar{\gamma}$ is optimal if $N_{c}>\underline{N}_{c}^{o}$ and $\gamma=0$ is optimal if $N_{c}<\underline{N}_{c}^{o}$. Because (34) and (30) result in sgn $\left[\widehat{\phi}^{*}-\widehat{\phi}^{o}\right]=\operatorname{sgn}\left[w_{c}-b\right]$, we know that $\underline{N}_{c}^{*}>\underline{N}_{c}^{o}$, implying Proposition 6. Figure 3 describes when the equilibrium decision on social interactions is optimal and when it is not.

\section{[Insert Figure 3 here]}

From the comparative statics results (Table 1), we know that the urban population size becomes larger when the total population size increases. Thus, the results of Proposition 6 imply that, as the total population grows, the economy experiences steady urbanization. During this process, the social-interaction decision is efficient only at an early and a late stage of urbanization but not at an intermediary stage of urbanization. The source of this inefficiency is due to (positive) 
externalities related to the decision on interacting with weak ties. Indeed, social interactions with weak ties make it more likely for an unemployed worker belonging to a $d_{1}$ dyad to find a job and thus to switch to a $d_{2}$ dyad. This implies that a higher level of social interactions increases the number of employed workers in $d_{2}$ dyads, which, in turn, raises the possibility of job information transmission through weak ties (i.e. increases $g^{*}$ ) for $d_{1}$ dyads. However, an unemployed worker in a $d_{1}$ dyad ignores this positive externality on other unemployed workers when making her social-interaction decision $\gamma$, resulting in inefficiency of this decision.

Next, we move to the efficiency analysis of urban population size, $N_{c}^{*}$. In order to focus on the properties of urbanization, we mainly restrict our attention to the cases where the equilibrium decision on social interactions is efficient (i.e., $\gamma^{*}=\gamma^{o}$, or equivalently, $N_{c} \leq \underline{N}_{c}^{o}$ or $N_{c}>\underline{N}_{c}^{*}$ ). In such cases, the equilibrium condition for $N_{c}^{*},(24)$, is equal to

$$
\Omega=\left\{\begin{array}{l}
\left.W_{0 c}^{u}\right|_{\gamma=0} \text { for } \gamma=0 \\
\left.W_{0 c}^{u}\right|_{\gamma=\bar{\gamma}} \text { for } \gamma=\bar{\gamma}
\end{array}\right.
$$

whereas the optimal condition is given by

$$
\Omega=\left\{\begin{array}{l}
\left.\Theta_{t}^{o}\right|_{\gamma=0} \text { for } \gamma=0 \\
\left.\Theta_{t}^{o}\right|_{\gamma=\bar{\gamma}} \text { for } \gamma=\bar{\gamma}
\end{array}\right.
$$

where $\left.\Theta_{t}^{o}\right|_{\gamma=0}$ and $\left.\Theta_{t}^{o}\right|_{\gamma=\bar{\gamma}}$ are defined in (65). As shown in the proof of propositions 6 and 7 in the Appendix, we have that: $\left.W_{0 c}^{u}\right|_{\gamma=0}>\left.\Theta_{t}^{o}\right|_{\gamma=0}$ and $\left.W_{0 c}^{u}\right|_{\gamma=\bar{\gamma}}>\left.\Theta_{t}^{o}\right|_{\gamma=\bar{\gamma}}$, which implies that the curves of $\left.W_{0 c}^{u}\right|_{\gamma=0}$ and $\left.W_{0 c}^{u}\right|_{\gamma=\bar{\gamma}}$ are above the curves of $\left.\Theta_{t}^{o}\right|_{\gamma=0}$ and $\left.\Theta_{t}^{o}\right|_{\gamma=\bar{\gamma}}$, as can be seen in Figures 4(a) and 4(b), respectively.

[Insert Figures $4(a)$ and 4(b) here]

We have the following proposition.

Proposition 7 When the equilibrium level of social interactions is optimal $\left(\gamma^{*}=\gamma^{o}\right)$, the equilibrium urbanization level $N_{c}^{*}$ is always higher than the optimal level one $N_{c}^{o}$.

Such over-urbanization partly arises from the search frictions in the urban labor market. Indeed, when deciding whether to migrate or not, each migrant compares the discounted sum of expected income. Given the existence of urban unemployment, such decision leads to overurbanization (as in, e.g., Harris and Todaro, 1970). In addition, in the Full-Interaction equilibrium, there exists agglomeration (positive) externalities and congestion (negative) externalities from finding jobs via weak ties. Indeed, when a worker decides to migrate to the city, it increases the size of the urban population and thus the possibility of contacting a weak tie, which 
is represented by the term $\phi\left(N_{c}\right)$ in $g(t)$. This creates positive agglomeration externalities. At the same time, the decision to migrate increases the number of workers in $d_{0}$ dyads, which, in turn, increases the number of workers in $d_{1}$ dyads. This, in turn, decreases the possibility of job information transmission from a weak tie, which is represented by the term $d_{2} / d_{1}$ in $g(t)$. This results in the congestion negative externality. Here, the effect of the negative externality dominates the effect of the positive one, and this is why we observe over-urbanization even in the Full-Interaction equilibrium as compared to the social optimum. Finally, we can briefly comment on the case for which $\gamma^{*} \neq \gamma^{o}$ (i.e., $\underline{N}_{c}^{o}<N_{c} \leq \underline{N}_{c}^{*}$ ). In this case, although we cannot determine analytically the efficiency properties of $N_{c}^{*}$, simple numerical examples indicate that $\left.W_{0 c}^{u}\right|_{\gamma=\bar{\gamma}}>\left.\Theta_{t}^{o}\right|_{\gamma=0} \cdot{ }^{14}$ Therefore, it would be safe to conclude that this economy experiences too much urbanization in general.

In summary, there are two market failures. The first one stems form social interactions (at intermediate levels of urban population) so that there are too few social interactions in equilibrium. The second comes from urbanization. When social interactions are optimal, which corresponds to either small or large cities, there is too much agglomeration or urbanization in equilibrium.

\section{Conclusion}

We develop a model where unemployed workers in the city can find a job either directly or through weak or strong ties. We show that, in denser areas, individuals interact with more people and have more random encounters (weak ties) than in sparsely populated areas. We also demonstrate that, for low urbanization levels, there is a unique steady-state No-Interaction equilibrium where workers do not interact with weak ties, while, for high level of urbanization, there is a unique steady-state Full-Interaction equilibrium with full social interactions. Thus, if we consider a continuous growth process of total population size, there will be a regime change from the No-Interaction equilibrium to the Full-Interaction equilibrium in the city. We show that these equilibria are usually not socially efficient when the urban population has an intermediate size because there are too few social interactions compared to the social optimum. When the equilibrium level of social interactions is optimal, the equilibrium urbanization level is always higher than the optimal level one, leading to over-urbanization.

\footnotetext{
${ }^{14}$ We tried two specifications of $\phi\left(N_{c}\right)$ (i.e., $\phi\left(N_{c}\right)=N_{c} /\left(1+N_{c}\right)$ and $\left.\phi\left(N_{c}\right)=1-\exp \left[-N_{c}\right]\right)$. We also tried various sets of parameter values. For any combination, we obtained that $\left.W_{0 c}^{u}\right|_{\gamma=\bar{\gamma}}>\left.\Theta_{t}^{o}\right|_{\gamma=0}$. These simulation results are available upon request.
} 
There are many empirical studies that try to measure agglomeration economies in different cities (see, for example, Glaeser, 2010). However, few studies have put forward the role of social interactions and social networks in agglomeration and urbanization. Usually, following Marshall (1890) and Jacobs (1969), authors have emphasized the role that cities can play in speeding the flow of ideas. The interactions of smart and skilled people in urban areas enhances the development of person-specific human capital and increases the rate at which new ideas are formed. We believe that the role of social interactions and the fact that people tend to extend their social networks by meeting more weak ties in bigger cities that help them find a job are crucial in explaining agglomeration. We also believe that this can lead to over-urbanization, which would imply that cities are oversized. These issues certainly need more thorough empirical investigations.

\section{References}

[1] Akerlof, G. (1997), "Social distance and social decisions," Econometrica 65, 1005-1027.

[2] Amato, P.R. (1993), "Urban-rural differences in helping friends and family members," Social Psychology Quarterly 56, 249-262.

[3] Ballester, C., Calvó-Armengol, A. and Y. Zenou (2006), "Who's who in networks. Wanted: The key player," Econometrica 74, 1403-1417.

[4] Bayer, P., Ross, S.L. and G. Topa (2008), "Place of work and place of residence: Informal hiring networks and labor market outcomes," Journal of Political Economy 116, 1150-1196.

[5] Beckmann, M.J. (1976), "Spatial equilibrium and the dispersed city," In: Y.Y. Papageorgiou (Ed.), Mathematical Land Use Theory, Lexington, MA: Lexington Books, pp. 117-125.

[6] Brueckner, J.K. and A.G. Largey (2008), "Social interaction and urban sprawl," Journal of Urban Economics 64, 18-34.

[7] Brueckner, J.K., Thisse, J-F. and Y. Zenou (2002), "Local labor markets, job matching and urban location," International Economic Review 43, 155-171.

[8] Calvó-Armengol, A. and M.O. Jackson (2004), "The effects of social networks on employment and inequality," American Economic Review 94, 426-454. 
[9] Calvó-Armengol, A., Verdier, T. and Y. Zenou (2007), "Strong and weak ties in employment and crime," Journal of Public Economics 91, 203-233.

[10] Cattell V. (2001), "Poor people, poor places, and poor health: The mediating role of social networks and social capital," Social Science and Medicine 52, 1501-1516.

[11] Coleman, J.S. (1988), "Social capital in the creation of human capital," American Journal of Sociology 94, S95-S120.

[12] Desmond, M. (2012), "Disposable ties and the urban poor," American Journal of Sociology $117,1295-1335$.

[13] Fischer, C. (1982), To Dwell Among Friends: Personal Networks in Town and City, Chicago: University of Chicago Press.

[14] Fujita, M. and J.-F. Thisse (2013), Economics of Agglomeration. Cities, Industrial Location, and Globalization, 2nd Edition, Cambridge: Cambridge University Press.

[15] Ghiglino, C. and A. Nocco (2012), "When Veblen meets Krugman," Unpublished manuscript, University of Essex.

[16] Glaeser, E.L. (2010), Agglomeration Economics, Chicago: University of Chicago Press.

[17] Glaeser, E.L., Sacerdote, B. and J.A. Scheinkman (1996), "Crime and social interactions," Quarterly Journal of Economics 111, 508-548.

[18] Granovetter, M.S. (1973), "The strength of weak ties," American Journal of Sociology 78, $1360-1380$.

[19] Granovetter, M.S. (1974), Getting a Job: A Study of Contacts and Careers, Cambridge, MA: Harvard University Press.

[20] Granovetter, M.S. (1983), "The strength of weak ties: A network theory revisited," Sociological Theory 1, 201-233.

[21] Grauwin, S., Goffette-Nagot, F. and P. Jensen (2012), "Dynamic models of residential segregation: An analytical solution," Journal of Public Economics 96, 124-141.

[22] Harris, J.R. and M.P. Todaro (1970), "Migration, unemployment and development: A twosector analysis," American Economic Review 60, 126-142. 
[23] Hellerstein, J.K., McInerney, M. and D. Neumark (2011), "Neighbors and coworkers: The importance of residential labor market networks," Journal of Labor Economics 29, 659-695.

[24] Helsey, R.W. and W.C. Strange (2007), "Urban interactions and spatial structure," Journal of Economic Geography 7, 119-138.

[25] Helsley, R.W. and Y. Zenou (2014), "Social networks and interactions in cities," Journal of Economic Theory, forthcoming.

[26] Ioannides, Y.M. and D.L. Loury (2004), "Job information networks, neighborhood effects, and inequality," Journal of Economic Literature 42, 1056-1093.

[27] Ioannides, Y.M. and G. Topa (2010), "Neighborhood effects: Accomplishments and looking beyond them," Journal of Regional Science 50, 343-362.

[28] Ioannides, Y.M. (2012), From Neighborhoods to Nations: The Economics of Social Interactions, Princeton: Princeton University Press.

[29] Jacobs, J. (1969), The Economy of Cities, New York: Vintage.

[30] Korte, C. (1980), "Urban-nonurban differences in social behavior and social psychological models of urban impact," Journal of Social Issues 36, 29-51.

[31] Lin, N. and M. Dumin (1986), "Access to occupations through social ties," Social Networks $8,365-386$.

[32] Maloney, W.F. (1999), "Does informality imply segmentation in urban labor markets? Evidence from sectoral transitions in Mexico," World Bank Economic Review 13, 275-302.

[33] Marcouiller, D., Ruiz de Castilla, V. and C. Woodruff (1997), "Formal measures of the informal-sector wage gap in Mexico, El Salvador, and Peru," Economic Development and Cultural Change 45, 367-392.

[34] Marshall, A. (1890), Principles of Economics, London: Macmillan.

[35] Mossay, P. and P.M. Picard (2011), "On spatial equilibria in a social interaction model," Journal of Economic Theory 146, 2455-2477.

[36] Mossay, P. and P.M. Picard (2013), "Spatial segregation and urban structure," Unpublished manuscript, University of Luxemburg. 
[37] Palisi, B.J. and C. Canning (1986), "Urbanism and social psychological well-being: A test of three theories," Sociological Spectrum 6, 361-378.

[38] Patacchini, E. and Y. Zenou (2012), "Ethnic networks and employment outcomes," Regional Science and Urban Economics 42, 938-949.

[39] Pissarides, C.A. (2000), Equilibrium Unemployment Theory, Second edition, Cambridge, MA: MIT Press.

[40] Putnam, R.D. (1993), Making Democracy Work: Civic Traditions in Modern Italy, Princeton: Princeton University Press.

[41] Putnam, R.D. (2001), Bowling Alone, New York: Simon and Schuster.

[42] Schelling, T.C. (1971), "Dynamic models of segregation," Journal of Mathematical Sociology $1,143-186$.

[43] Simmel, G. (1995), "The metropolis and mental life," In: P. Kasnitz (Ed.), Metropolis: Center and Symbol of our Times, Basingstoke: Macmillan, pp. 30-45.

[44] Topa, G. (2001), "Social interactions, local spillovers and unemployment," Review of Economic Studies 68, 261-295.

[45] Tonnies, F. (1957), Community and Society, East Lansing, MI: Michigan State University Press.

[46] Wahba, J, and Y. Zenou (2005), "Density, social networks and job search methods: Theory and application to Egypt," Journal of Development Economics 78 443-473.

[47] Wellman, B. (1979), "The community question: The intimate networks of East Yorkers," American Journal of Sociology 84, 1201-1231.

[48] Wirth, L. (1938), "Urbanism as a way of life," American Journal of Sociology 44, 1-24.

[49] Yamada, G. (1996), "Urban informal employment and self-employment in developing countries: Theory and evidence," Economic Development and Cultural Change 44, 289-314.

[50] Zenou, Y. (2011), "Search, migration, and urban land use. The case of transportation policies," Journal of Development Economics 96, 174-187.

[51] Zenou, Y. (2013), "Spatial versus social mismatch," Journal of Urban Economics 74, 113132. 
[52] Zenou, Y. (2014), "A dynamic model of weak and strong ties in the labor market," Unpublished manuscript, Stockholm University.

[53] Zhang, J. (2004), "Residential segregation in an all-integrationist world," Journal of Economic Behavior and Organization 54, 533-550. 


\section{Appendix: Proofs}

Proof of Proposition 1: Let us determine the optimal $\gamma$. Unemployed workers in a $d_{1}^{*}$ dyad choose $\gamma$ that maximize $W_{1 c}^{u}$, taking as given $N_{c}^{*}, d_{1}^{*}$ and $d_{2}^{*}$. Using (21) and (18), we obtain

$$
\begin{aligned}
\frac{\partial W_{1 c}^{u}}{\partial \gamma}= & \frac{\left[-\beta+2 \lambda \phi\left(N_{c}^{*}\right) \frac{d_{2}^{*}}{d_{1}^{*}} \frac{w_{c}}{r+\delta}\right]\left(r+\delta+g^{*}\right)-\left(b-\beta \gamma+g^{*} \frac{w_{c}}{r+\delta}\right) 2 \lambda \phi\left(N_{c}^{*}\right) \frac{d_{2}^{*}}{d_{1}^{*}}}{\left(r+\delta+g^{*}\right)^{2}} \\
= & \frac{-\beta\left(r+\delta+g^{*}\right)+\frac{w_{x}}{r+\delta}\left(r+\delta+g^{*}\right) 2 \lambda \phi\left(N_{c}^{*}\right) \frac{d_{2}^{*}}{d_{1}^{*}}-(b-\beta \gamma) 2 \lambda \phi\left(N_{c}^{*}\right) \frac{d_{2}^{*}}{d_{1}^{*}}-g^{*} \frac{w_{c}}{r+\delta} 2 \lambda \phi\left(N_{c}^{*}\right) \frac{d_{2}^{*}}{d_{1}^{*}}}{\left(r+\delta+g^{*}\right)^{2}} \\
= & \frac{-\beta\left[r+\delta+2 \lambda+\gamma 2 \lambda \phi\left(N_{c}^{*}\right) \frac{d_{2}^{*}}{d_{1}^{*}}\right]+\frac{w_{c}}{r+\delta}(r+\delta) 2 \lambda \phi\left(N_{c}^{*}\right) \frac{d_{2}^{*}}{d_{1}^{*}}-(b-\beta \gamma) 2 \lambda \phi\left(N_{c}^{*}\right) \frac{d_{2}^{*}}{d_{1}^{*}}}{\left(r+\delta+g^{*}\right)^{2}} \\
= & \frac{-\beta(r+\delta+2 \lambda)+w_{c} 2 \lambda \phi\left(N_{c}^{*}\right) \frac{d_{2}^{*}}{d_{1}^{*}}-b 2 \lambda \phi\left(N_{c}^{*}\right) \frac{d_{2}^{*}}{d_{1}^{*}}}{\left(r+\delta+g^{*}\right)^{2}} \\
= & \frac{d_{2}^{*}}{d_{1}^{*}} \frac{2 \lambda \phi\left(N_{c}^{*}\right)\left(w_{c}-b\right)-\beta \frac{d_{1}^{*}}{d_{2}^{*}}(r+\delta+2 \lambda)}{\left(r+\delta+g^{*}\right)^{2}}
\end{aligned}
$$

This implies that

$$
\operatorname{sgn}\left[\frac{\partial W_{1 c}^{u}}{\partial \gamma}\right]=\operatorname{sgn}\left[2 \lambda \phi\left(N_{c}^{*}\right)\left(w_{c}-b\right)-\beta \frac{d_{1}^{*}}{d_{2}^{*}}(r+\delta+2 \lambda)\right]
$$

Using (9) and (10), we see that

$$
\frac{d_{1}^{*}}{d_{2}^{*}}=\frac{\delta}{2 \lambda}-\gamma \phi\left(N_{c}^{*}\right)
$$

Plugging $\frac{d_{1}^{*}}{d_{2}^{*}}$ into the above equation, we can see that

$$
\operatorname{sgn}\left[\frac{\partial W_{1 c}^{u}}{\partial \gamma}\right]=\operatorname{sgn}\left[2 \lambda \phi\left(N_{c}^{*}\right)\left(w_{c}-b\right)+\beta\left(\gamma \phi\left(N_{c}^{*}\right)-\frac{\delta}{2 \lambda}\right)(r+\delta+2 \lambda)\right] .
$$

This leads to

$$
\frac{\partial W_{1 c}^{u}}{\partial \gamma} \gtreqless 0 \Leftrightarrow \gamma \gtreqless \frac{\delta}{2 \lambda \phi\left(N_{c}^{*}\right)}-\frac{2 \lambda\left(w_{c}-b\right)}{\beta(r+\delta+2 \lambda)}
$$

This condition only depends on $N_{c}^{*}$. We therefore know that an unemployed worker in the $d_{1}^{*}$ dyad choose either $\gamma=0$ (no interaction at all with weak ties) or $\gamma=\bar{\gamma}$ (maximum interaction with weak ties), i.e. we have only corner solutions.

Let us characterize all the solutions of this maximization problem.

(i) If

$$
\frac{\delta}{2 \lambda \phi\left(N_{c}^{*}\right)}<\frac{2 \lambda\left(w_{c}-b\right)}{\beta(r+\delta+2 \lambda)}
$$

which is equivalent to

$$
\phi\left(N_{c}^{*}\right)>\frac{\delta \beta(r+\delta+2 \lambda)}{4 \lambda^{2}\left(w_{c}-b\right)}
$$


then $\gamma^{*}=\bar{\gamma}$. Since $\phi^{\prime}()>$.0 , this means that, if $N_{c}^{*}>\bar{N}_{c}$, then $\gamma^{*}=\bar{\gamma}$, where

$$
\bar{N}_{c} \equiv \phi^{-1}\left(\frac{\delta \beta(r+\delta+2 \lambda)}{4 \lambda^{2}\left(w_{c}-b\right)}\right)
$$

(ii) If

$$
\frac{\delta}{2 \lambda \phi\left(N_{c}^{*}\right)}-\frac{2 \lambda\left(w_{c}-b\right)}{\beta(r+\delta+2 \lambda)}>\bar{\gamma}
$$

which is equivalent to

$$
\phi\left(N_{c}^{*}\right)<\frac{\delta \beta(r+\delta+2 \lambda)}{4 \lambda^{2}\left(w_{c}-b\right)+2 \lambda \bar{\gamma} \beta(r+\delta+2 \lambda)}
$$

then $\gamma^{*}=0$. Since $\phi^{\prime}()>$.0 , this means that, if $N_{c}^{*}<\underline{N}_{c}$, then $\gamma^{*}=0$, where

$$
\underline{N}_{c} \equiv \phi^{-1}\left(\frac{\delta \beta(r+\delta+2 \lambda)}{4 \lambda^{2}\left(w_{c}-b\right)+2 \lambda \bar{\gamma} \beta(r+\delta+2 \lambda)}\right)
$$

(iii) If

$$
0<\frac{\delta}{2 \lambda \phi\left(N_{c}^{*}\right)}-\frac{2 \lambda\left(w_{c}-b\right)}{\beta(r+\delta+2 \lambda)}<\bar{\gamma}
$$

then both cases $\gamma^{*}=0$ and $\gamma^{*}=\bar{\gamma}$ can arise.

Figure A1 illustrates these different cases.

\section{[Insert Figure A1 here]}

Let us now deal with case $($ iii $)$ only since the other cases are straightforward. Then, using the fact that $\bar{\gamma}=b / \beta, W_{1 c}^{u}$ can be written as:

$$
\begin{gathered}
\left.W_{1 c}^{u}\right|_{\gamma=0}=\frac{b+\frac{2 \lambda w_{c}}{r+\delta}}{r+\delta+2 \lambda} \\
\left.W_{1 c}^{u}\right|_{\gamma=\bar{\gamma}}=\frac{2 \lambda \delta w_{c}}{(r+\delta)\left[\beta \delta(r+\delta+2 \lambda)-2 b \lambda(r+\delta) \phi\left(N_{c}^{*}\right)\right]}
\end{gathered}
$$

Comparing the asset values under no social interaction $(\gamma=0)$ to that under full social interaction $(\gamma=\bar{\gamma})$, we can see that $\left.W_{1 c}^{u}\right|_{\gamma=0}=\left.W_{1 c}^{u}\right|_{\gamma=\bar{\gamma}}$ if and only if

$$
\phi\left(N_{c}^{*}\right)=\widehat{\phi} \equiv \frac{\beta \delta(r+\delta+2 \lambda)}{2 \lambda\left[b(r+\delta)+2 w_{c} \lambda\right]}
$$

Furthermore, we have that

$$
\frac{\partial\left(\left.W_{1 c}^{u}\right|_{\gamma=\bar{\gamma}}-\left.W_{1 c}^{u}\right|_{\gamma=0}\right)}{\partial \phi\left(N_{c}\right)}=\frac{\partial\left(\left.W_{1 c}^{u}\right|_{\gamma=\bar{\gamma}}\right)}{\partial \phi\left(N_{c}\right)}=\frac{4 b \beta w_{c} \delta \lambda^{2}}{\left[\beta \delta(r+\delta+2 \lambda)-2 b \lambda \phi\left(N_{c}\right)(r+\delta)\right]^{2}}>0
$$

As a result, an unemployed worker in the $d_{1}^{*}$ dyad always chooses $\gamma^{*}=\bar{\gamma}$ if and only if $\phi\left(N_{c}\right)>\widehat{\phi}$ and chooses $\gamma^{*}=0$ if and only if $\phi\left(N_{c}\right)<\widehat{\phi}$. From the assumption that $\phi^{\prime}\left(N_{c}\right)>0$, we have a threshold regarding the city population: $\widehat{N}_{c} \equiv \phi^{-1}(\widehat{\phi})$, i.e.

$$
\widehat{N}_{c} \equiv \phi^{-1}\left(\frac{\beta \delta(r+\delta+2 \lambda)}{2 \lambda\left[b(r+\delta)+2 w_{c} \lambda\right]}\right)
$$


Since $\bar{\gamma}=b / \beta$, then it is easily verified that $\widehat{N}_{c}=\underline{N}_{c}$, given by (25). Observe also that

$$
\widehat{N}_{c}=\underline{N}_{c}<\bar{N}_{c}
$$

which implies that an unemployed worker in the $d_{1}^{*}$ dyad always chooses $\gamma=\bar{\gamma}$ in case (iii). Proposition 1 summarizes these results.

Proof of Proposition 2: Using (23), the steady-state migration equilibrium condition (24) can be written as

$$
W_{0 c}^{u}=\frac{f^{\prime}\left(N-N_{c}\right)}{(r+\delta)}
$$

Hence, the equilibrium conditions given in Proposition 1 (see the proof of Proposition 1) become

$$
\begin{array}{ll}
\frac{f^{\prime}\left(N-N_{c}\right)}{r+\delta}=\left.W_{0 c}^{u}\right|_{\gamma=0}=\frac{b+\lambda\left(W_{c}^{e}+\left.W_{1 c}^{u}\right|_{\gamma=0}\right)}{r+\delta+2 \lambda} & \text { if and only if } N_{c}<\underline{N}_{c}, \\
\frac{f^{\prime}\left(N-N_{c}\right)}{r+\delta}=\left.W_{0 c}^{u}\right|_{\gamma=\bar{\gamma}}=\frac{b+\lambda\left(W_{c}^{e}+\left.W_{1 c}^{u}\right|_{\gamma=\bar{\gamma}}\right)}{r+\delta+2 \lambda} \quad \text { if and only if } N_{c} \geq \underline{N}_{c} .
\end{array}
$$

From these conditions, we obtain Proposition 2.

Let us first characterize the No-Interaction Equilibrium for which all workers provide zero effort, i.e. $\gamma^{*}=0$. Using (8), (9) and (10) and the fact that $\gamma=0$, we easily obtain:

$$
d_{0}^{*}=\frac{\delta N_{c}^{*}}{2(\delta+2 \lambda)}, d_{1}^{*}=\frac{\lambda \delta N_{c}^{*}}{(\delta+2 \lambda)^{2}}, d_{2}^{*}=\frac{2 \lambda^{2} N_{c}^{*}}{(\delta+2 \lambda)^{2}}
$$

Since the urban unemployment level is: $U_{c}^{*}=2 d_{0}^{*}+d_{1}^{*}$, we obtain:

$$
U^{*}=\frac{\delta(\delta+3 \lambda) N_{c}^{*}}{(\delta+2 \lambda)^{2}}
$$

From (18), we obtain:

$$
g^{*}=2 \lambda
$$

From (20), (21), (22) and (23), we have:

$$
\begin{gathered}
\left.W_{0 c}^{u *}\right|_{\gamma=0}=\frac{(r+\delta)(r+\delta+3 \lambda) b+\lambda(r+\delta+4 \lambda) w_{c}}{(r+\delta)(r+\delta+2 \lambda)^{2}} \\
\left.W_{1 c}^{u *}\right|_{\gamma=0}=\frac{(r+\delta) b+2 \lambda w_{c}}{(r+\delta)(r+\delta+2 \lambda)} \\
W_{c}^{e *}=\frac{w_{c}}{r+\delta} \\
\Omega=\frac{f^{\prime}\left(N-N_{c}^{*}\right)}{r+\delta}
\end{gathered}
$$


Finally, the migration equilibrium condition (24) is given by $W_{0 c}^{u}=f^{\prime}\left(N-N_{c}\right) /(r+\delta)$. By using (40), this equation (24) can be written as

$$
f^{\prime}\left(N-N_{c}^{*}\right)=\frac{(r+\delta)(r+\delta+3 \lambda) b+\lambda(r+\delta+4 \lambda) w_{c}}{(r+\delta+2 \lambda)^{2}}
$$

which implicitly defined $N_{c}^{*}$.

Let us now characterize the Full-Interaction Equilibrium for which all workers provide maximal effort, i.e. $\gamma^{*}=\bar{\gamma}$. Proceeding exactly as above, we easily obtain:The equilibrium values are given by:

$$
\begin{gathered}
d_{0}^{*}=\frac{\delta N_{c}^{*}}{2(\delta+2 \lambda)}, d_{1}^{*}=\frac{2 \lambda^{2} N_{c}^{*}}{(\delta+2 \lambda)\left[\delta+2 \lambda\left(1-\bar{\gamma} \phi\left(N_{c}^{*}\right)\right)\right]}\left[\frac{\delta}{2 \lambda}-\bar{\gamma} \phi\left(N_{c}^{*}\right)\right] \\
d_{2}^{*}=\frac{2 \lambda^{2} N_{c}^{*}}{(\delta+2 \lambda)\left[\delta+2 \lambda\left(1-\bar{\gamma} \phi\left(N_{c}^{*}\right)\right)\right]} \\
U^{*}=\frac{\delta(\delta+3 \lambda)-2 \lambda \bar{\gamma} \phi\left(N_{c}^{*}\right)(\delta+\lambda)}{(\delta+2 \lambda)\left[\delta+2 \lambda\left(1-\bar{\gamma} \phi\left(N_{c}^{*}\right)\right)\right]} N_{c}^{*} \\
g^{*}=\frac{2 \delta \lambda}{\delta-2 \lambda \gamma \phi\left(N_{c}^{*}\right)} \\
W_{0 c}^{u}=\frac{\beta \delta\left[b(r+\delta)(r+\delta+2 \lambda)+\lambda w_{c}(r+\delta+4 \lambda)\right]-2 b \lambda \phi\left(N_{c}^{*}\right)(r+\delta)\left[b(r+\delta)+\lambda w_{c}\right]}{(r+\delta)(r+\delta+2 \lambda)\left[\delta \beta(r+\delta+2 \lambda)-2 \lambda b \phi\left(N_{c}^{*}\right)(r+\delta)\right]} \\
W_{1 c}^{u}=\frac{w_{c}}{(r+\delta)\left[\beta \delta(r+\delta+2 \lambda)-2 b \lambda \phi\left(N_{c}^{*}\right)(r+\delta)\right]}, W_{c}^{e}=\frac{f^{\prime}\left(N-N_{c}^{*}\right)}{r+\delta}, \\
f^{\prime}\left(N-N_{c}^{*}\right)=\frac{\beta \delta\left[b(r+\delta)(r+\delta+2 \lambda)+\lambda w_{c}(r+\delta+4 \lambda)\right]-2 b \lambda \phi\left(N_{c}^{*}\right)(r+\delta)\left[b(r+\delta)+\lambda w_{c}\right]}{(r+\delta+2 \lambda)\left[\delta \beta(r+\delta+2 \lambda)-2 \lambda b \phi\left(N_{c}^{*}\right)(r+\delta)\right]}
\end{gathered}
$$

This completes the proof.

Proof of Proposition 3: To show that there is a unique equilibrium with $\gamma^{*}=0$, we need to show that $\left.\left.W_{0 c}^{u}\right|_{\gamma=0}\right|_{N_{c}=0}>f^{\prime}(N) /(r+\delta)$. This is equivalent to:

$$
(r+\delta)(r+\delta+3 \lambda) b+\lambda(r+\delta+4 \lambda) w_{c}>(r+\delta+2 \lambda)^{2} f^{\prime}(N)
$$

To show that there is a unique equilibrium with $\gamma^{*}=\bar{\gamma}$, we further need to show that $\left.\Omega^{\prime}\left(N_{c}\right)\right|_{N_{c}=N_{c}^{*}}>$ $\left.\partial W_{0 c}^{u}\right|_{\gamma=\bar{\gamma}} /\left.\partial N_{c}\right|_{N_{c}=N_{c}^{*}}$. This is equivalent to:

$$
-(r+\delta+2 \lambda)\left[1+\bar{\gamma} \phi\left(N_{c}^{*}\right)\right]^{2} f^{\prime \prime}\left(N-N_{c}^{*}\right)>\frac{4 \lambda^{3} w_{c}(2 \lambda+\delta)(r+\delta) \bar{\gamma} \phi^{\prime}\left(N_{c}^{*}\right)}{\left\{(r+\delta)\left[\frac{\delta-2 \lambda \bar{\gamma} \phi\left(N_{c}^{*}\right)}{1+\bar{\gamma} \phi\left(N_{c}^{*}\right)}\right]+4 \lambda^{2}\right\}^{2}}
$$

This completes the proof. 
Proof of Propositions 4: In the No-interaction equilibrium, the urban population size, $N_{c}^{*}$, is determined by (51). By totally differentiating (51), we obtain, after straightforward but tedious calculations, the following results of basic comparative statics:

$$
\begin{gathered}
\frac{\partial N_{c}^{*}}{\partial \delta}=\frac{b(r+\delta)^{2}(r+\delta+4 \lambda)+2 w_{c} \lambda\left[r^{2}+\delta^{2}+6 \delta \lambda+4 \lambda^{2}+2 r(\delta+3 \lambda)\right]}{f^{\prime \prime}\left(N-N_{c}^{*}\right)(r+\delta)(r+\delta+2 \lambda)^{3}}<0 \\
\frac{\partial N_{c}^{*}}{\partial \lambda}=-\frac{\left(w_{c}-b\right)(r+\delta)(r+\delta+6 \lambda)}{f^{\prime \prime}\left(N-N_{c}^{*}\right)(r+\delta+2 \lambda)^{3}}>0 \\
\frac{\partial N_{c}^{*}}{\partial b}=-\frac{(r+\delta)(r+\delta+3 \lambda)}{f^{\prime \prime}\left(N-N_{c}^{*}\right)(r+\delta+2 \lambda)^{2}}>0 \\
\frac{\partial N_{c}^{*}}{\partial w_{c}}=-\frac{\lambda(r+\delta+4 \lambda)}{f^{\prime \prime}\left(N-N_{c}^{*}\right)(r+\delta+2 \lambda)^{2}}>0 \\
\frac{\partial N_{c}^{*}}{\partial N}=1>0 \\
\frac{\partial N_{c}^{*}}{\partial r}=\frac{b(r+\delta)^{2}(r+\delta+4 \lambda)+2 w_{c} \lambda\left[r^{2}+\delta^{2}+6 \delta \lambda+4 \lambda^{2}+2 r(\delta+3 \lambda)\right]}{f^{\prime \prime}\left(N-N_{c}^{*}\right)(r+\delta)(r+\delta+2 \lambda)^{3}}<0
\end{gathered}
$$

The equilibrium unemployment rate is defined by

$$
u^{*}=\frac{U^{*}}{N}
$$

where $U^{*}$ is given by (38). Hence, we readily obtain

$$
\begin{gathered}
\frac{\partial u^{*}}{\partial \delta}=\frac{N_{c}^{*} \lambda(\delta+6 \lambda)+\delta(\delta+2 \lambda)(\delta+3 \lambda) \frac{\partial N_{c}^{*}}{\partial \delta}}{N(\delta+2 \lambda)^{3}} \\
\frac{\partial u^{*}}{\partial \lambda}=\frac{\delta\left[-N_{c}^{*}(\delta+6 \lambda)+\left(\delta^{2}+5 \delta \lambda+6 \lambda^{2}\right) \frac{\partial N_{c}^{*}}{\partial \lambda}\right]}{N(\delta+2 \lambda)^{3}} \\
\frac{\partial u^{*}}{\partial b}=\frac{\delta(\delta+3 \lambda)}{N(\delta+2 \lambda)^{2}} \frac{\partial N_{c}^{*}}{\partial b}>0 \\
\frac{\partial u^{*}}{\partial w_{c}}=\frac{\delta(\delta+3 \lambda)}{N(\delta+2 \lambda)^{2}} \frac{\partial N_{c}^{*}}{\partial w_{c}}>0 \\
\frac{\partial u^{*}}{\partial N}=\frac{\delta(\delta+3 \lambda)\left(-N_{c}^{*}+N \frac{\partial N_{c}^{*}}{\partial N}\right)}{N^{2}(\delta+2 \lambda)^{2}}=\frac{\delta(\delta+3 \lambda)\left(N-N_{c}^{*}\right)}{N^{2}(\delta+2 \lambda)^{2}}>0
\end{gathered}
$$




$$
\frac{\partial u^{*}}{\partial r}=\frac{\delta(\delta+3 \lambda)}{N(\delta+2 \lambda)^{2}} \frac{\partial N_{c}^{*}}{\partial r}<0
$$

This completes the proof.

Proof of Propositions 5: Here, we assume that (53) holds, i.e.,

$$
\left.\Omega^{\prime}\left(N_{c}\right)\right|_{N_{c}=N_{c}^{*}}-\left.\frac{\left.\partial W_{0 c}^{u}\right|_{\gamma=\bar{\gamma}}}{\partial N_{c}}\right|_{N_{c}=N_{c}^{*}}>0
$$

to ensure that the model has the unique Full-interaction equilibrium. In the Full-interaction equilibrium, the urban population size is determined by (51). By totally differentiating (51), we can obtain

$$
\begin{aligned}
& \frac{\partial N_{c}^{*}}{\partial \delta}=\left[\left.\Omega^{\prime}\left(N_{c}\right)\right|_{N_{c}=N_{c}^{*}}-\left.\frac{\left.\partial W_{0 c}^{u}\right|_{\gamma=\bar{\gamma}}}{\partial N_{c}}\right|_{N_{c}=N_{c}^{*}}\right]^{-1}\left\{-\frac{b(r+\delta)^{2}}{(r+\delta)^{2}(r+\delta+2 \lambda)^{2}}\right. \\
& -\frac{2 w_{c} \lambda \beta^{2} \delta^{2}(r+\delta+2 \lambda)\left[(r+\delta)^{2}+6(r+\delta) \lambda+4 \lambda^{2}\right]}{(r+\delta)^{2}(r+\delta+2 \lambda)^{2}\left[\beta \delta(r+\delta+2 \lambda)-2 b(r+\delta) \lambda \phi\left(N_{c}^{*}\right)\right]^{2}} \\
& +\frac{4 w_{c} \lambda^{2} b \beta(r+\delta)\left[2 \delta(r+\delta)^{2}-(r-8 \delta)(r+\delta) \lambda-2(r-3 \delta) \lambda^{2}\right] \phi\left(N_{c}^{*}\right)}{(r+\delta)^{2}(r+\delta+2 \lambda)^{2}\left[\beta \delta(r+\delta+2 \lambda)-2 b(r+\delta) \lambda \phi\left(N_{c}^{*}\right)\right]^{2}} \\
& \left.-\frac{8 w_{c} \lambda^{3} b^{2}(r+\delta)^{2}(r+\delta+\lambda) \phi\left(N_{c}^{*}\right)^{2}}{(r+\delta)^{2}(r+\delta+2 \lambda)^{2}\left[\beta \delta(r+\delta+2 \lambda)-2 b(r+\delta) \lambda \phi\left(N_{c}^{*}\right)\right]^{2}}\right\} \\
& \frac{\partial N_{c}^{*}}{\partial \lambda}=\left[\left.\Omega^{\prime}\left(N_{c}\right)\right|_{N_{c}=N_{c}^{*}}-\left.\frac{\left.\partial W_{0 c}^{u}\right|_{\gamma=\bar{\gamma}}}{\partial N_{c}}\right|_{N_{c}=N_{c}^{*}}\right]^{-1} \\
& \times\left\{\frac{\beta^{2} \delta^{2}(r+\delta+2 \lambda)\left[w_{c}(r+\delta+6 \lambda)-2 b(r+\delta+2 \lambda)\right]}{(r+\delta+2 \lambda)^{2}\left[\beta \delta(r+\delta+2 \lambda)-2 b(r+\delta) \lambda \phi\left(N_{c}^{*}\right)\right]^{2}}\right. \\
& +\frac{4 b \beta \delta(r+\delta) \lambda\left[2 b(r+\delta+2 \lambda)-w_{c}(r+\delta+3 \lambda)\right] \phi\left(N_{c}^{*}\right)}{(r+\delta+2 \lambda)^{2}\left(\beta \delta(r+\delta+2 \lambda)-2 b(r+\delta) \lambda \phi\left(N_{c}^{*}\right)\right)^{2}} \\
& \left.-\frac{4 b^{2}\left(2 b-w_{c}\right)(r+\delta)^{2} \lambda^{2} \phi\left(N_{c}^{*}\right)^{2}}{(r+\delta+2 \lambda)^{2}\left(\beta \delta(r+\delta+2 \lambda)-2 b(r+\delta) \lambda \phi\left(N_{c}^{*}\right)\right)^{2}}\right\} \\
& \frac{\partial N_{c}^{*}}{\partial b}=\left[\left.\Omega^{\prime}\left(N_{c}\right)\right|_{N_{c}=N_{c}^{*}}-\left.\frac{\left.\partial W_{0 c}^{u}\right|_{\gamma=\bar{\gamma}}}{\partial N_{c}}\right|_{N_{c}=N_{c}^{*}}\right]^{-1} \\
& \times\left\{\frac{\beta^{2} \delta^{2}(r+\delta+2 \lambda)^{2}+4 \beta \delta \lambda\left[w_{c} \lambda^{2}-b(r+\delta)(r+\delta+2 \lambda)\right] \phi\left(N_{c}^{*}\right)}{(r+\delta+2 \lambda)\left[\beta \delta(r+\delta+2 \lambda)-2 b(r+\delta) \lambda \phi\left(N_{c}^{*}\right)\right]^{2}}\right. \\
& \left.+\frac{4 b^{2}(r+\delta)^{2} \lambda^{2} \phi\left(N_{c}^{*}\right)^{2}}{(r+\delta+2 \lambda)\left[\beta \delta(r+\delta+2 \lambda)-2 b(r+\delta) \lambda \phi\left(N_{c}^{*}\right)\right]^{2}}\right\}
\end{aligned}
$$




$$
\begin{aligned}
& \frac{\partial N_{c}^{*}}{\partial w_{c}}=\left[\left.\Omega^{\prime}\left(N_{c}\right)\right|_{N_{c}=N_{c}^{*}}-\left.\frac{\left.\partial W_{0 c}^{u}\right|_{\gamma=\bar{\gamma}}}{\partial N_{c}}\right|_{N_{c}=N_{c}^{*}}\right]^{-1} \\
& \times \frac{\lambda\left[\beta \delta(r+\delta+4 \lambda)-2 b(r+\delta) \lambda \phi\left(N_{c}^{*}\right)\right]}{(r+\delta)(r+\delta+2 \lambda)\left[\beta \delta(r+\delta+2 \lambda)-2 b(r+\delta) \lambda \phi\left(N_{c}^{*}\right)\right]} \\
& >0 \\
& \begin{aligned}
\frac{\partial N_{c}^{*}}{\partial N} & =-\frac{f^{\prime \prime}\left(N-N_{c}^{*}\right)}{r+\delta}\left[\left.\Omega^{\prime}\left(N_{c}\right)\right|_{N_{c}=N_{c}^{*}}-\left.\frac{\left.\partial W_{0 c}^{u}\right|_{\gamma=\bar{\gamma}}}{\partial N_{c}}\right|_{N_{c}=N_{c}^{*}}\right]^{-1} \\
& =-\frac{f^{\prime \prime}\left(N-N_{c}^{*}\right)}{r+\delta}\left[-\frac{f^{\prime \prime}\left(N-N_{c}^{*}\right)}{r+\delta}-\left.\frac{\left.\partial W_{0 c}^{u}\right|_{\gamma=\bar{\gamma}}}{\partial N_{c}}\right|_{N_{c}=N_{c}^{*}}\right]^{-1}
\end{aligned} \\
& >1 \\
& \begin{aligned}
\frac{\partial N_{c}^{*}}{\partial r}=[ & \left.\left.\Omega^{\prime}\left(N_{c}\right)\right|_{N_{c}=N_{c}^{*}}-\left.\frac{\left.\partial W_{0 c}^{u}\right|_{\gamma=\bar{\gamma}}}{\partial N_{c}}\right|_{N_{c}=N_{c}^{*}}\right]^{-1} \\
& \times\left\{-\frac{(r+\delta)\left[b(r+\delta)+w_{c} \lambda\right]+w_{c} \lambda(r+\delta+2 \lambda)}{(r+\delta)^{2}(r+\delta+2 \lambda)^{2}}\right. \\
& \left.+\frac{\frac{4 w_{c} \beta^{2} \delta^{2} \lambda^{3}(r+\delta+2 \lambda)}{(\beta \delta(r+\delta+2 \lambda)-2 b(r+\delta) \lambda \phi)^{2}}-\frac{2 w_{c} \beta \delta \lambda^{2}(3(r+\delta)+4 \lambda)}{\beta \delta(r+\delta+2 \lambda)-2 b(r+\delta) \lambda \phi}}{(r+\delta)^{2}(r+\delta+2 \lambda)^{2}}\right\}
\end{aligned}
\end{aligned}
$$

where the inequality in (55) comes from assumptions (54) and (19) which states that $\delta>2 \bar{\gamma} \bar{\phi} \lambda$, and the inequality in (56) comes from (54) and the assumption that $f^{\prime \prime}(\cdot) \leq 0$.

In the Full-interaction equilibrium, $U^{*}$ is given by (47). Hence, we can see that

$$
\begin{gathered}
\frac{\partial u^{*}}{\partial \delta}=\frac{\beta(\delta+2 \lambda)\left\{\beta \lambda N_{c}^{*}(\delta+6 \lambda)+\frac{\partial N_{c}^{*}}{\partial \delta}\left[\beta \delta(\delta+2 \lambda)(\delta+3 \lambda)-4 b \lambda^{3} N_{c}^{*} \phi^{\prime}\left(N_{c}^{*}\right)\right]\right\}}{N(\delta+2 \lambda)^{2}\left[\beta(\delta+2 \lambda)-2 b \lambda \phi\left(N_{c}^{*}\right)\right]^{2}} \\
-\frac{4 b \beta \lambda \phi\left(N_{c}^{*}\right)\left[\lambda N_{c}^{*}(\delta+3 \lambda)+\frac{\partial N_{c}^{*}}{\partial \delta}(\delta+2 \lambda)\left(\delta^{2}+3 \delta \lambda+\lambda^{2}\right)\right]}{N(\delta+2 \lambda)^{2}\left[\beta(\delta+2 \lambda)-2 b \lambda \phi\left(N_{c}^{*}\right)\right]^{2}} \\
+\frac{4 b^{2} \lambda^{2} \phi\left(N_{c}^{*}\right)^{2}\left[\lambda N_{c}^{*}+\frac{\partial N_{c}^{*}}{\partial \delta}(\delta+\lambda)(\delta+2 \lambda)\right]}{N(\delta+2 \lambda)^{2}\left[\beta(\delta+2 \lambda)-2 b \lambda \phi\left(N_{c}^{*}\right)\right]^{2}}
\end{gathered}
$$




$$
\begin{aligned}
& \frac{\partial u^{*}}{\partial \lambda}=\frac{\frac{\partial N_{c}^{*}}{\partial \lambda}(\delta+2 \lambda)\left[\beta(\delta+2 \lambda)-2 b \lambda \phi\left(N_{c}^{*}\right)\right]\left[\beta \delta(\delta+3 \lambda)-2 b \lambda(\delta+\lambda) \phi\left(N_{c}^{*}\right)\right]}{N(\delta+2 \lambda)^{2}\left[\beta(\delta+2 \lambda)-2 b \lambda \phi\left(N_{c}^{*}\right)\right]^{2}} \\
& -\frac{N_{c}^{*} \beta\left[4 b \lambda^{3} \frac{\partial N_{c}^{*}}{\partial \lambda} \phi^{\prime}\left(N_{c}^{*}\right)+\beta \delta(\delta+6 \lambda)\right]}{N(\delta+2 \lambda)\left[\beta(\delta+2 \lambda)-2 b \lambda \phi\left(N_{c}^{*}\right)\right]^{2}} \\
& +\frac{4 b \delta \lambda N_{c}^{*} \phi\left(N_{c}^{*}\right)\left[\beta(\delta+3 \lambda)-b \lambda \phi\left(N_{c}^{*}\right)\right]}{N(\delta+2 \lambda)^{2}\left[\beta(\delta+2 \lambda)-2 b \lambda \phi\left(N_{c}^{*}\right)\right]^{2}} \\
& \frac{\partial u^{*}}{\partial b}=\frac{-4 N_{c}^{*} \beta \lambda^{3} \phi+\frac{\partial N_{c}^{*}}{\partial b}\left\{\beta^{2} \delta(\delta+2 \lambda)(\delta+3 \lambda)+4 b^{2} \lambda^{2}(\delta+\lambda) \phi\left(N_{c}^{*}\right)^{2}\right.}{N(\delta+2 \lambda)\left[\beta(\delta+2 \lambda)-2 b \lambda \phi\left(N_{c}^{*}\right)\right]^{2}} \\
& -\frac{\left.4 b \beta \lambda\left[\lambda^{2} N_{c}^{*} \phi^{\prime}\left(N_{c}^{*}\right)+\left(\delta^{2}+3 \delta \lambda+\lambda^{2}\right) \phi\left(N_{c}^{*}\right)\right]\right\}}{N(\delta+2 \lambda)\left[\beta(\delta+2 \lambda)-2 b \lambda \phi\left(N_{c}^{*}\right)\right]^{2}} \\
& \frac{\partial u^{*}}{\partial w_{c}}=\frac{\partial N_{c}^{*}}{\partial w_{c}}\left\{\frac{\beta^{2} \delta\left(\delta^{2}+5 \delta \lambda+4 \lambda^{2}\right)-4 b \beta \lambda\left(\delta^{2}+3 \delta \lambda+\lambda^{2}\right) \phi\left(N_{c}^{*}\right)}{N(\delta+2 \lambda)\left[\beta(\delta+2 \lambda)-2 b \lambda \phi\left(N_{c}^{*}\right)\right]^{2}}\right. \\
& \left.+\frac{2 \lambda^{2}\left[2 b^{2}(\delta+\lambda) \phi\left(N_{c}^{*}\right)^{2}+\beta^{2} \delta-2 b \beta \lambda N_{c}^{*} \phi^{\prime}\left(N_{c}^{*}\right)\right]}{N(\delta+2 \lambda)\left[\beta(\delta+2 \lambda)-2 b \lambda \phi\left(N_{c}^{*}\right)\right]^{2}}\right\} \\
& >0 \\
& \frac{\partial u^{*}}{\partial N}=-\frac{1}{N^{2}(\delta+2 \lambda)}\left\{\left(N_{c}^{*}-N \frac{\partial N_{c}^{*}}{\partial N}\right) \frac{\delta \beta(\delta+3 \lambda)-(\delta+\lambda) 2 b \lambda \phi\left(N_{c}^{*}\right)}{\beta(\delta+2 \lambda)-2 b \lambda \phi\left(N_{c}^{*}\right)}\right. \\
& \left.+\frac{4 b \beta \lambda^{3} N N_{c}^{*} \phi^{\prime}\left(N_{c}^{*}\right)}{\left(\beta(\delta+2 \lambda)-2 b \lambda \phi\left(N_{c}^{*}\right)\right)^{2}} \frac{\partial N_{c}^{*}}{\partial N}\right\} \\
& <0 \\
& \begin{array}{r}
\frac{\partial u^{*}}{\partial r}=\frac{\frac{\partial N_{c}^{*}}{\partial r}\left\{\beta^{2} \delta(\delta+2 \lambda)(\delta+3 \lambda)+4 b^{2} \lambda^{2}(\delta+\lambda) \phi\left(N_{c}^{*}\right)^{2}\right.}{N(\delta+2 \lambda)\left[\beta(\delta+2 \lambda)-2 b \lambda \phi\left(N_{c}^{*}\right)\right]^{2}} \\
-\frac{\left.4 b \beta \lambda\left[\lambda^{2} N_{c}^{*} \phi^{\prime}\left(N_{c}^{*}\right)+\phi\left(N_{c}^{*}\right)\left(\delta^{2}+3 \delta \lambda+\lambda^{2}\right)\right]\right\}}{N(\delta+2 \lambda)\left[\beta(\delta+2 \lambda)-2 b \lambda \phi\left(N_{c}^{*}\right)\right]^{2}}
\end{array}
\end{aligned}
$$

where the inequality in (57) comes from assumption of concavity of $\phi(\cdot)$ and assumption (19) which states that $\delta>2 \bar{\gamma} \bar{\phi} \lambda$, and the inequality in (58) comes from the facts that $\partial N_{c}^{*} / \partial N>1$ and $N>N_{c}^{*}$, and assumption (19). 
Proof of Propositions 6 and 7: Using (27) and (28), the Hamiltonian can be written as:

$$
\begin{aligned}
H_{t}=e^{-r t} & \left\{f\left(N-N_{c}(t)\right)+\left[2 d_{2}(t)+d_{1}(t)\right] w_{c}+\left[N_{c}(t)-2 d_{2}(t)-d_{1}(t)\right] b-\beta d_{1}(t) \gamma(t)\right\} \\
& \left.+\mu_{1}(t)\left\{2 \lambda\left(\frac{N_{c}(t)}{2}-d_{1}(t)-d_{2}(t)\right)-\left[\delta+2 \lambda\left(1+\frac{\gamma d_{2}(t)}{d_{1}(t)} \phi\left(N_{c}(t)\right)\right)\right] d_{1}(t)\right]\right\} \\
& +\mu_{2}(t)\left[2 \lambda\left(1+\frac{\gamma d_{2}(t)}{d_{1}(t)} \phi\left(N_{c}(t)\right)\right) d_{1}(t)-\delta d_{2}(t)\right]
\end{aligned}
$$

Moreover, we need to consider the inequality constraints $\gamma \geq 0$ and $\bar{\gamma} \geq \gamma$. The Lagrangian for the maximization problem becomes

$$
\mathcal{L}_{t}=H_{t}+\xi_{0} \gamma+\xi_{1}(\bar{\gamma}-\gamma)
$$

The first-order conditions for the maximization are

$$
\begin{aligned}
N_{c}(t): & 0=\frac{\partial \mathcal{L}_{t}}{\partial N_{c}(t)}, \\
\gamma(t): & 0=\frac{\partial \mathcal{L}_{t}}{\partial \gamma(t)}, \\
d_{1}: & \dot{\mu}_{1}(t)=-\frac{\partial \mathcal{L}_{t}}{\partial d_{1}(t)}, \\
d_{2}: & \dot{\mu}_{2}(t)=-\frac{\partial \mathcal{L}_{t}}{\partial d_{2}(t)},
\end{aligned}
$$

This is equivalent to

$$
\begin{gathered}
0=\frac{\partial H_{t}}{\partial N_{c}(t)}=e^{-r t}\left[-f^{\prime}\left(N-N_{c}(t)\right)+b\right]+\mu_{1} \lambda \\
0=\frac{\partial H_{t}}{\partial \gamma(t)}+\xi_{0}-\xi_{1}=-e^{-r t} \beta d_{1}(t)+2 \lambda \phi\left(N_{c}(t)\right) d_{2}(t)\left[\mu_{2}(t)-\mu_{1}(t)\right]+\xi_{0}-\xi_{1} \\
\dot{\mu}_{1}(t)=-e^{-r t}\left(w_{c}-b-\beta \gamma\right)+\mu_{1}(t)(\delta+4 \lambda)-2 \mu_{2}(t) \lambda \\
\dot{\mu}_{2}(t)=-2 e^{-r t}\left(w_{c}-b\right)+2 \mu_{1}(t) \lambda\left[1+\gamma \phi\left(N_{c}(t)\right)\right]+\mu_{2}(t)\left[\delta-2 \gamma \lambda \phi\left(N_{c}(t)\right)\right]
\end{gathered}
$$

We evaluate the optimal allocation at the steady state. Then, the last two differential equations yield

$$
\begin{gathered}
\mu_{1}(t)=\frac{e^{-r t}}{\delta+2 \lambda}\left[w_{c}-b-\beta \gamma+\frac{2 \lambda\left(w_{c}-b+\beta \gamma\right)}{\delta+2 \lambda-2 \gamma \lambda \phi\left(N_{c}(t)\right)}\right] \\
\mu_{2}(t)=2 e^{-r t} \frac{\beta \gamma \lambda\left[1+\gamma \phi\left(N_{c}(t)\right)\right]+w_{c}\left[\delta+\lambda\left[3-\gamma \phi\left(N_{c}(t)\right)\right]\right]-b\left[\delta+\lambda\left[3-\gamma \phi\left(N_{c}(t)\right)\right]\right]}{(\delta+2 \lambda)\left[\delta+2 \lambda-2 \gamma \lambda \phi\left(N_{c}(t)\right)\right]}
\end{gathered}
$$

Equation (61) can be written as

$$
\frac{\partial H_{t}}{\partial \gamma(t)}=\xi_{1}-\xi_{0}
$$

which implies that the optimal $\gamma$ is a corner solution. If $\xi_{0}>0$ and $\xi_{1}=0$, then $\gamma^{o}=0$, whereas if $\xi_{0}=0$ and $\xi_{1}>0$, then $\gamma^{o}=\bar{\gamma}$. Substituting (62) and (63) into (61), we obtain: 


$$
\operatorname{sgn}\left[\frac{\partial H_{t}}{\partial \gamma(t)}\right]=\operatorname{sgn}\left[\beta\left[\gamma \phi\left(N_{c}(t)\right)-\frac{\delta}{2 \lambda}\right]+\frac{2 \lambda \phi\left(N_{c}(t)\right)\left(w_{c}-b-\beta \gamma\right)}{\delta+2 \lambda-2 \gamma \lambda \phi\left(N_{c}(t)\right)}\right] .
$$

Because we have assumed (19), i.e. $\delta>2 \bar{\gamma} \bar{\phi} \lambda$, then $\partial H_{t} / \partial \gamma(t)>0$ can be possible only when $w_{c}-b-\beta \bar{\gamma}=w_{c}-2 b>0$. Moreover, plugging the steady state conditions (8), (9) and (10), into the Hamiltonian (59), we obtain

$$
\left.H_{t}\right|_{\gamma=\bar{\gamma}}-\left.H_{t}\right|_{\gamma=0}=\frac{b N_{c}(t) \lambda\left[-\beta \delta(\delta+2 \lambda)+2 \lambda\left(b \delta+2 w_{c} \lambda\right) \phi\left(N_{c}(t)\right)\right]}{(\delta+2 \lambda)^{2}\left[\beta(\delta+2 \lambda)-2 b \lambda \phi\left(N_{c}(t)\right)\right]}
$$

Define

$$
\widehat{\phi}^{o} \equiv \frac{\beta \delta(\delta+2 \lambda)}{2 \lambda\left(b \delta+2 w_{c} \lambda\right)}
$$

From (64) and using (19), we know that if

$$
\left.\left.H_{t}\right|_{\gamma=\bar{\gamma}} \gtreqless H_{t}\right|_{\gamma=0} \Leftrightarrow \phi \gtreqless \widehat{\phi}^{o}
$$

Let $\underline{N}_{c}^{o}$ denote the urban population that satisfies

$$
\phi\left(\underline{N}_{c}^{o}\right)=\widehat{\phi}^{o}
$$

which means that

$$
\underline{N}_{c}^{o}=\phi^{-1}\left(\frac{\beta \delta(\delta+2 \lambda)}{2 \lambda\left(b \delta+2 w_{c} \lambda\right)}\right)
$$

Remember that $\widehat{\phi}^{*}$ was the equilibrium threshold defined by (34). Simple comparison yields

$$
\widehat{\phi}^{*}-\widehat{\phi}^{o}=\frac{r \beta \delta\left(w_{c}-b\right)}{\left(b \delta+2 w_{c} \lambda\right)\left[b(r+\delta)+2 w_{c} \lambda\right]}>0,
$$

implying that $\underline{N}_{c}^{*}>\underline{N}_{c}^{o}$.

Next, we examine whether the urbanization level is optimal when the equilibrium level of social interaction is efficient. Substituting $\mu_{1}(t)$ and $\mu_{2}(t)$ in (62) and (63) and using (60), we obtain that

$$
\Omega=\left\{\begin{array}{l}
\left.\Theta_{t}^{o}\right|_{\gamma=0} \text { for } \gamma=0 \\
\left.\Theta_{t}^{o}\right|_{\gamma=\bar{\gamma}} \text { for } \gamma=\bar{\gamma}
\end{array}\right.
$$

where $\left.\Theta_{t}^{o}\right|_{\gamma=0}$ and $\left.\Theta_{t}^{o}\right|_{\gamma=\bar{\gamma}}$ are defined by

$$
\begin{aligned}
&\left.\Theta_{t}^{o}\right|_{\gamma=0} \equiv \frac{b}{r+\delta}-\frac{\lambda\left(w_{c}-b\right)(\delta+4 \lambda)}{(r+\delta)(\delta+2 \lambda)(r+\delta+2 \lambda)}, \\
&\left.\Theta_{t}^{o}\right|_{\gamma=\bar{\gamma}} \equiv \frac{b}{r+\delta}-\frac{\lambda}{(r+\delta)(r+\delta+2 \lambda)}\left[w_{c}-2 b+\frac{2 \beta w_{c} \lambda}{c(\delta+2 \lambda)-2 b \lambda \phi\left(N_{c}(t)\right)}\right]
\end{aligned}
$$

and $\Omega$ is given by $(23)\left(\Omega \equiv f^{\prime}\left(N-N_{c}(t)\right) /(r+\delta)\right)$. In contrast, the equilibrium urbanization level is determined by

$$
\Omega=\left\{\begin{array}{l}
\left.W_{0 c}^{u}\right|_{\gamma=0} \text { for } \gamma=0 \\
\left.W_{0 c}^{u}\right|_{\gamma=\bar{\gamma}} \text { for } \gamma=\bar{\gamma}
\end{array}\right.
$$


where $\left.W_{0 c}^{u}\right|_{\gamma=0}$ and $\left.W_{0 c}^{u}\right|_{\gamma=\bar{\gamma}}$ are given by

$$
\left.W_{0 c}^{u}\right|_{\gamma=0}=\frac{b(r+\delta)(r+\delta+3 \lambda)+w_{c} \lambda(r+\delta+4 \lambda)}{(r+\delta)(r+\delta+2 \lambda)^{2}}
$$

and

$\left.W_{0 c}^{u}\right|_{\gamma=\bar{\gamma}}=\frac{\beta w_{c} \delta \lambda(r+\delta+4 \lambda)-2 b^{2} \lambda \phi\left(N_{c}(t)\right)(r+\delta)^{2}+b(r+\delta)\left[\beta \delta(r+\delta+2 \lambda)-2 w_{c} \lambda^{2} \phi\left(N_{c}(t)\right]\right.}{(r+\delta)(r+\delta+2 \lambda)\left[\beta \delta(r+\delta+2 \lambda)-2 b \lambda \phi\left(N_{c}(t)\right)(r+\delta)\right]}$

Taking the difference, we have:

$$
\left.W_{0 c}^{u}\right|_{\gamma=0}-\left.\Theta_{t}^{o}\right|_{\gamma=0}=\frac{2\left(w_{c}-b\right) \lambda[r(\delta+3 \lambda)+(\delta+2 \lambda)(\delta+4 \lambda)]}{(\delta+2 \lambda)(r+\delta+2 \lambda)^{2}}>0
$$

and

$$
\begin{aligned}
& \left.W_{0 c}^{u}\right|_{\gamma=\bar{\gamma}}-\left.\Theta_{t}^{o}\right|_{\gamma=\bar{\gamma}} \\
& =\frac{2 \lambda}{(r+\delta)(r+\delta+2 \lambda)}\left\{-2 b+w_{c}\left[1+\frac{\beta \lambda}{\beta(\delta+2 \lambda)-2 b \lambda \phi\left(N_{c}(t)\right)}\right.\right. \\
& \left.\left.\quad+\frac{\beta \lambda \delta}{\beta \delta(r+\delta+2 \lambda)-2 b(r+\delta) \lambda \phi\left(N_{c}(t)\right)}\right]\right\} \\
& >0
\end{aligned}
$$

where the last inequality comes from the fact that $\gamma=\bar{\gamma}$ can be optimal only when $w_{c}-2 b>0$, and assumption (19) which states that $\delta>2 \bar{\gamma} \bar{\phi} \lambda$. From figures 4(a) and 4(b), we obtain the results of the proposition. 


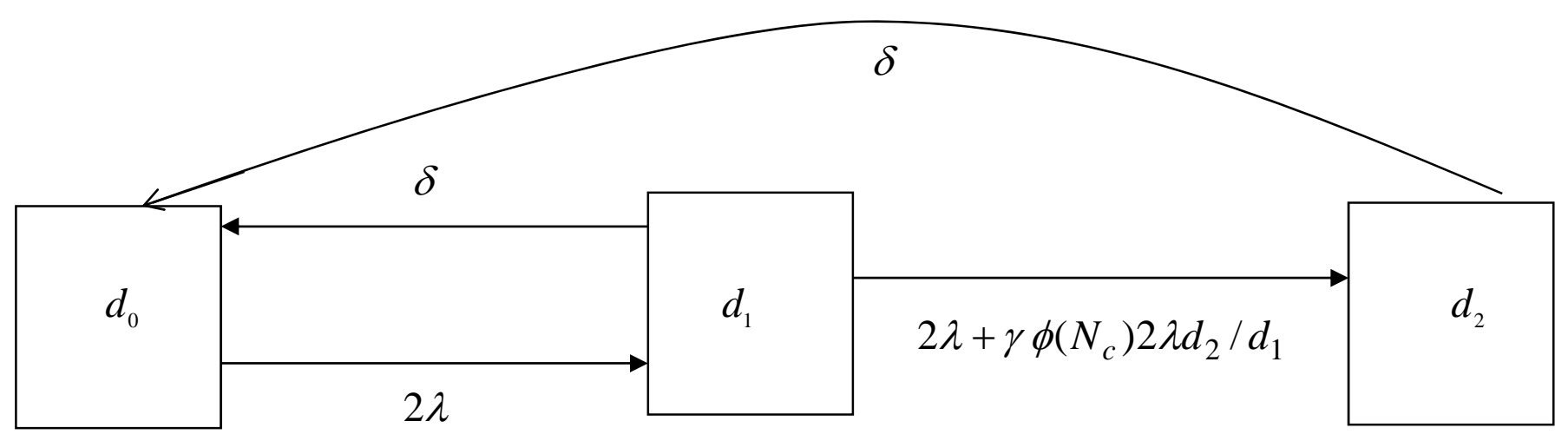

Figure 1: Flows in the labor market in steady state 


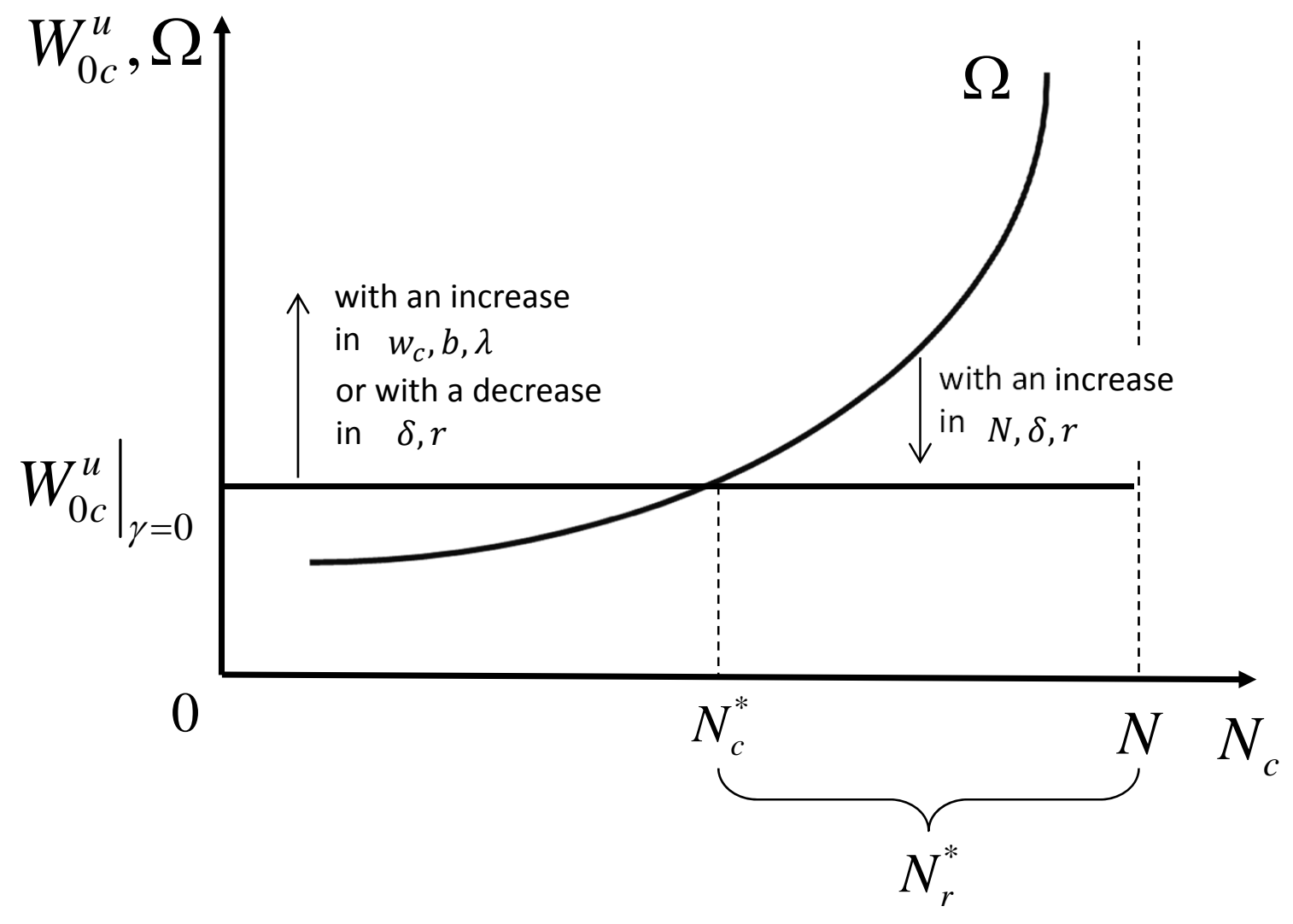

Figure 2(a): Equilibrium population distribution when there are no social interactions $\left(\gamma^{*}=0\right)$ 


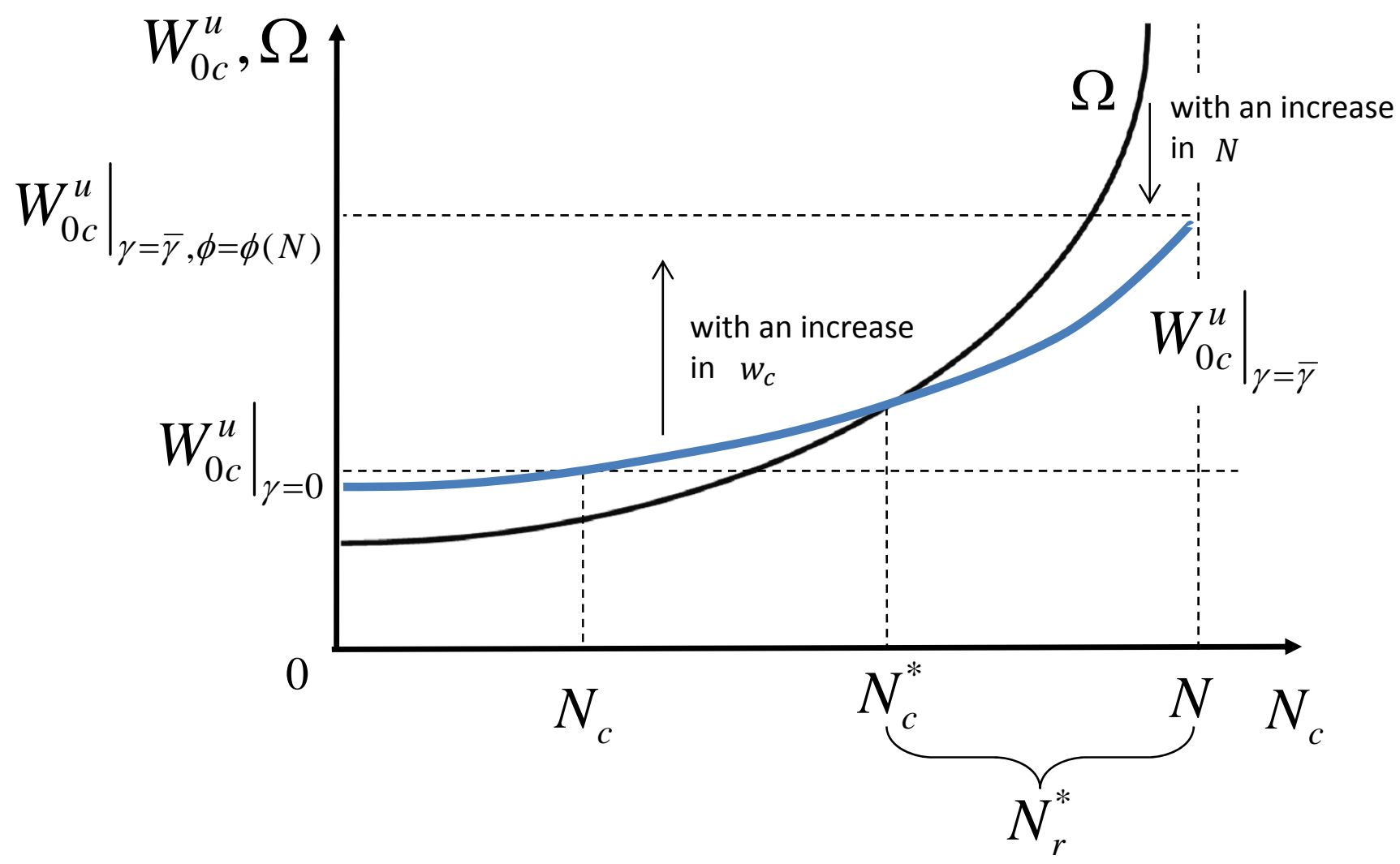

Figure 2(b): Equilibrium population distribution when there are full social interactions $(\gamma=\bar{\gamma})$ 


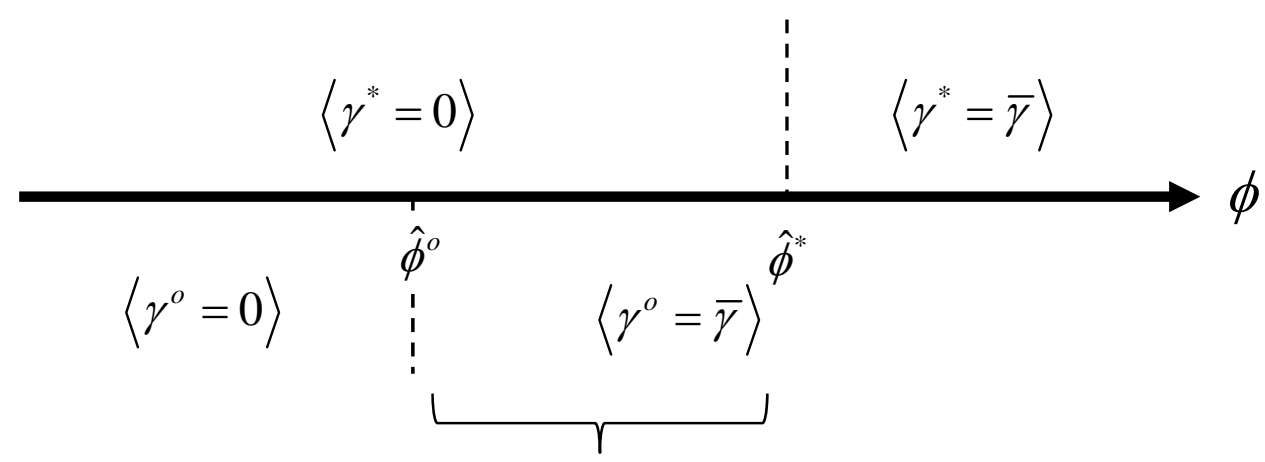

Too few social interactions

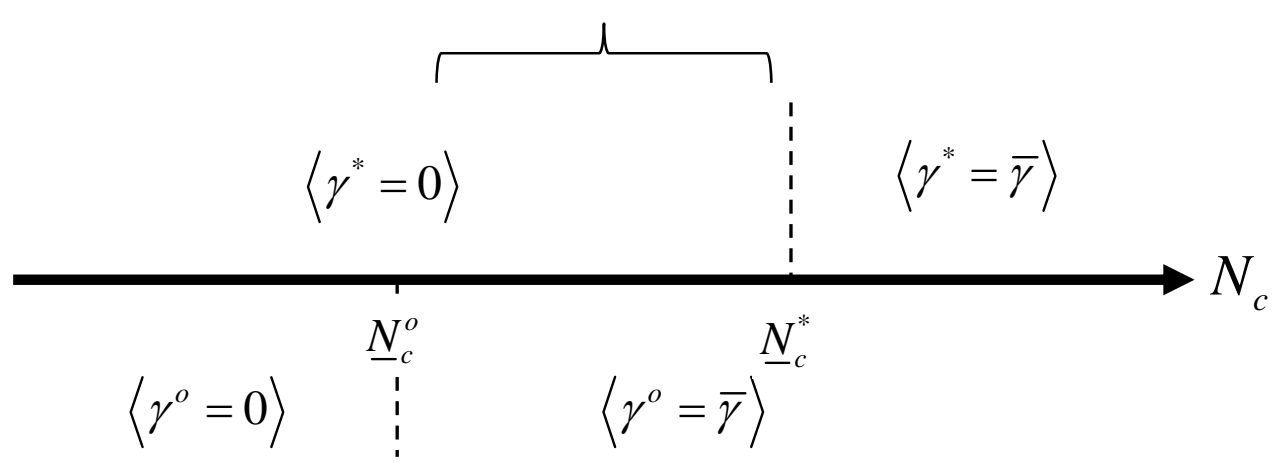

Figure 3: Equilibrium versus optimal social interactions 


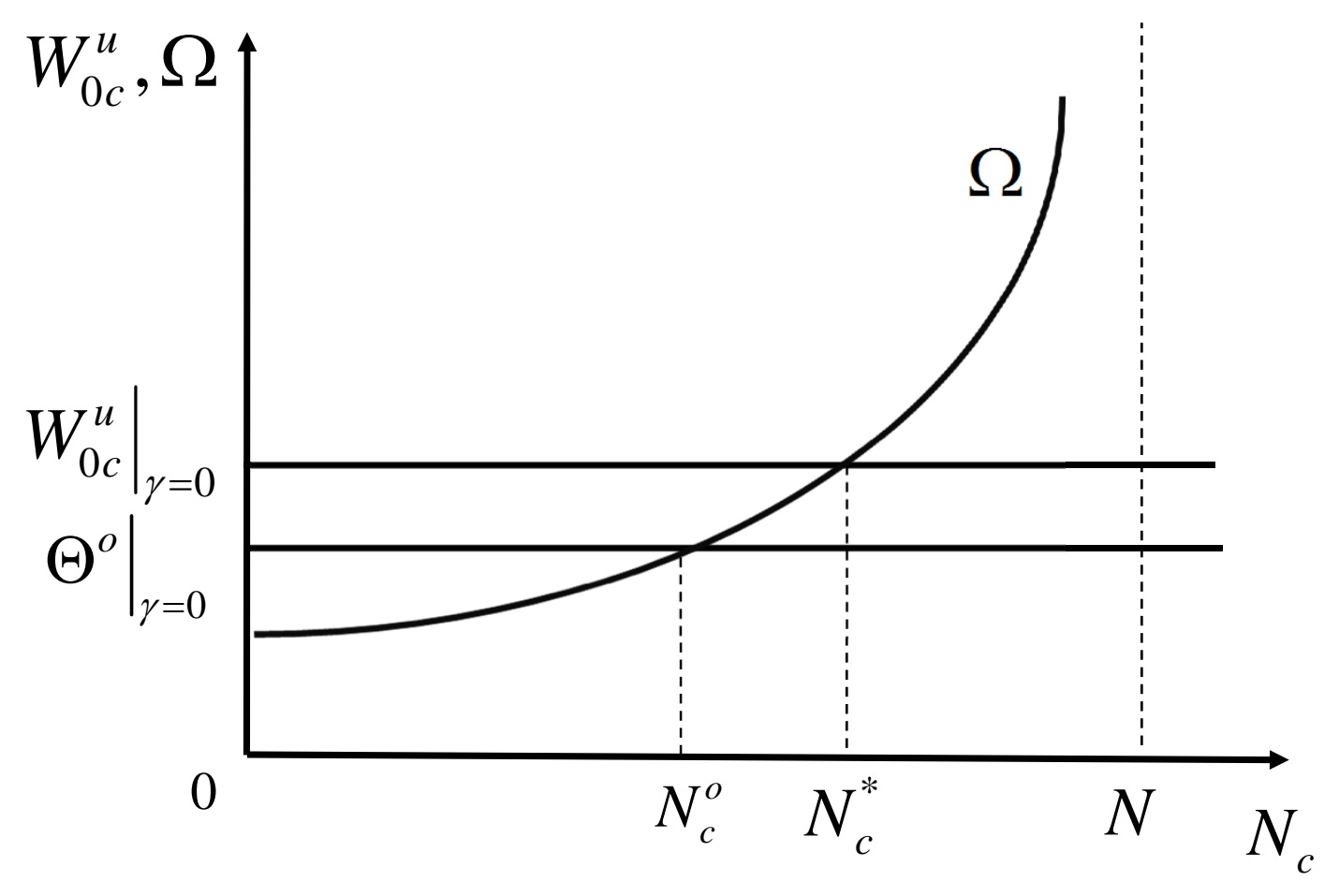

Figure 4(a): Equilibrium versus optimal population distribution when there are no social interactions $(\gamma=0)$ 


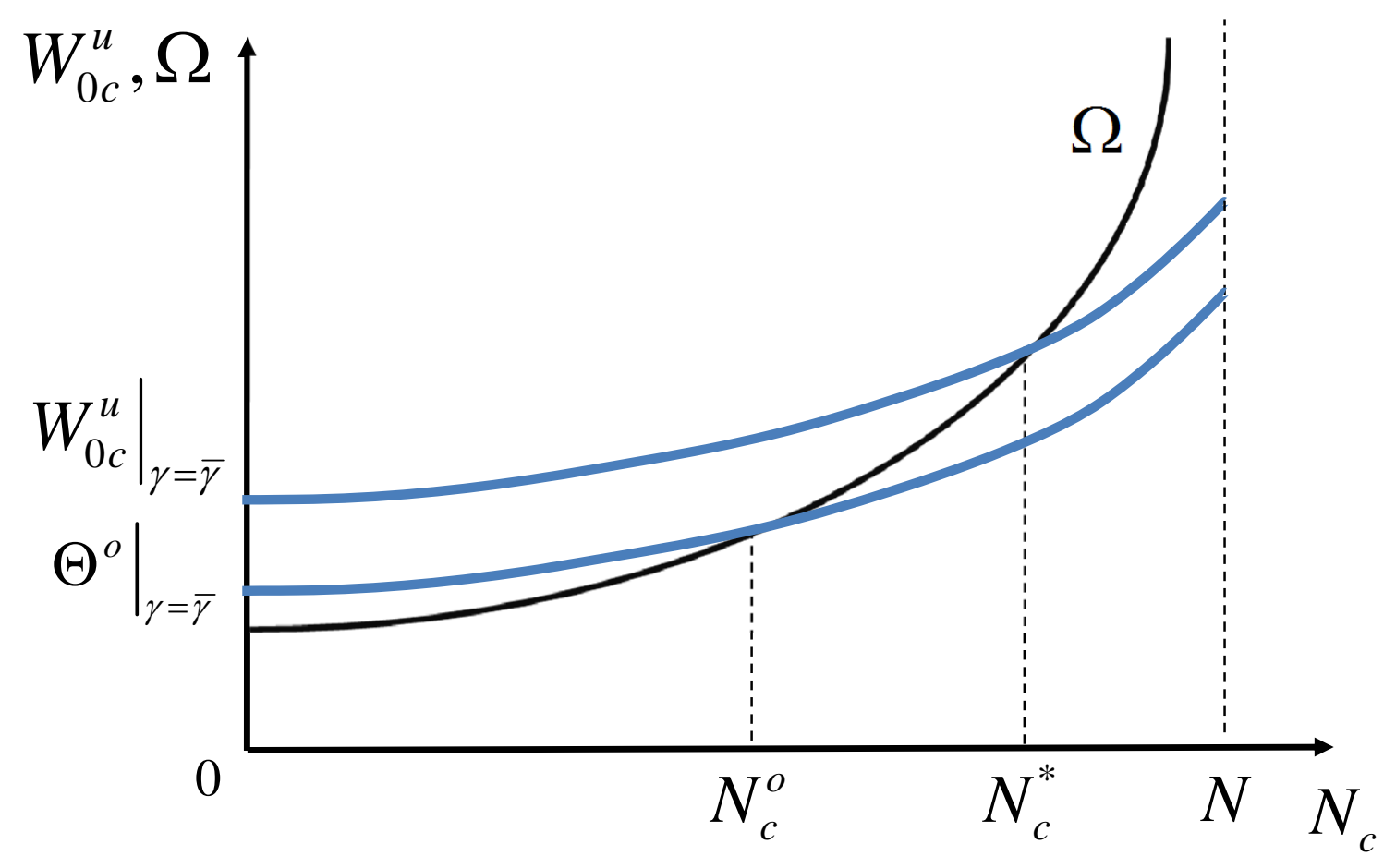

Figure 4(b): Equilibrium versus optimal population distribution when there are full social interactions $(\gamma=\bar{\gamma})$ 


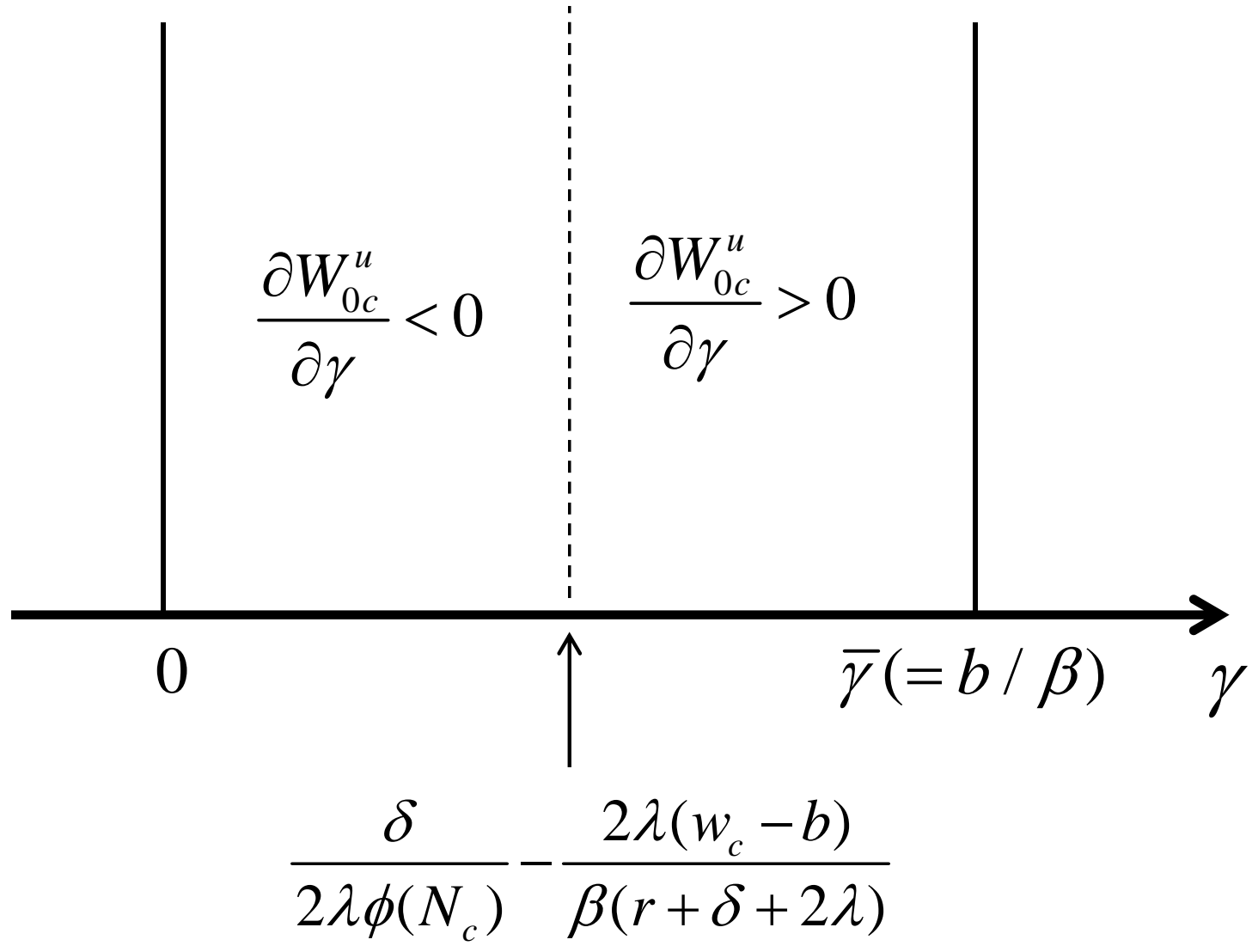

Figure A1: Optimal choice of social interactions 